\title{
HOW DO INDIVIDUALS INTERPRET MULTIPLE CONCEPTUAL MODELS? A THEORY OF COMBINED ONTOLOGICAL COMPLETENESS AND OVERLAP
}

\author{
Jan Recker \\ Faculty of Management, Economics and Social \\ Sciences \\ University of Cologne \\ Germany 50923 \\ and \\ School of Management \\ Queensland University of Technology \\ Australia 4000 \\ e-mail: jan.recker@wiso.uni-koeln.de; \\ j.recker@qut.edu.au
}

\author{
Peter Green \\ School of Accountancy \\ Queensland University of Technology \\ Australia 4000 \\ e-mail: p.green@qut.edu.au
}

Manuscript accepted for publication in the Journal of the Association for Information Systems as a Research Article.

\begin{abstract}
When analyzing or designing information systems, users often work with multiple conceptual models because each model articulates a different, partial aspect of a real-world domain. However, the available research in this area has largely studied the use of single modeling artefacts only. We develop new theory about interpreting multiple conceptual models that details propositions for evaluation of individuals' selection, understanding, and perceived usefulness of multiple conceptual models. We detail several implications of our theory development for empirical research on conceptual modeling. We also outline practical contributions for the design of conceptual models and for choosing models for systems analysis and design tasks. Finally, to stimulate research that builds on our theory, we illustrate procedures for enacting our theory and discuss a range of empirically relevant boundary conditions.
\end{abstract}

\section{Keywords}

Conceptual modeling, representation theory, combined ontological completeness, ontological overlap, model interpretation, model selection, domain understanding, perceived usefulness. 


\section{INTRODUCTION}

When analyzing or designing information systems (IS), professionals such as process analysts, systems designers, and software developers frequently develop and use representations of the relevant features of a real-world domain that the IS is intended to support. These representations, called conceptual models, describe someone's or some group's understanding of a real-world domain and the relevant features or phenomena in that domain (Wand and Weber, 2002).

Conceptual models are developed using grammars - that is, sets of constructs and the rules by which to combine them (Wand and Weber, 2002). The traditional focus of the academic literature on conceptual modeling has been on how the quality of grammars and models might be evaluated and improved (Burton-Jones et al., 2009; Siau and Rossi, 2011). However, the academic literature is inconsistent with practice. IS professionals typically do not use just one conceptual modeling grammar, let alone one conceptual model, in their analysis and design tasks. As we will show below, they use multiple models, often designed with different grammars, in their systems analysis and design practices. Yet, the literature offers no comprehensive theory yet to explain how practitioners would work with these models, to answer questions such as: which models do they choose as a representation to help them in an analysis or design task? How do they read multiple models together? Which models are useful together and which are not?

In this paper, we develop a new theory with which to analyze and explain the interpretation of multiple conceptual models in combination. We generate research models that specify detailed propositions regarding three important decisions when interpreting multiple models: selecting which models to use, determining how much domain understanding can be generated from multiple models, and explaining the perceived usefulness of conceptual model combinations. Because our aim is to invite future empirical research on conceptual modeling on the basis of 
theory, we also provide an illustration of the procedures with which the theory can be applied, and we discuss moderator variables that might be relevant in empirical research designs to establish boundary conditions.

In terms of contributions, to the best of our knowledge, this paper is the first paper to propose a theory to explain the interpretation of multiple conceptual models that is anchored in properties of the models themselves. This issue is important because, generally, when users model system requirements to ensure they have the requirements clear, they use many different models. When looked at in combination by other stakeholders who are trying to get a sense of the system, the combination of models, and symbolic constructs within the models, may not provide the full picture due to their lack of representation of a critical concept or they may confuse the stakeholders due to different symbols in different models actually representing the same real-world concept. Our work attempts to determine clearly and specifically the conditions under which any set of conceptual models can be viewed by stakeholders to minimize omitted or confused meaning. Moreover, while theoretical, our work also informs practice. By clarifying how multiple conceptual models might be meaningfully combined, we provide guidance to modeling practitioners on which model combinations are better for understanding domains, which are worse, and which will not cover various domains. Our work also informs model designers about model combinations they can create that will likely be of most benefit to future users.

We make one note about the theory development reported in this paper. The theory we produce is not grounded or derived inductively from data (Urquhart and Fernandez, 2013). Rather, it largely builds on established theory (Wand and Weber, 1990; 1993; 1995) and it derives new logic deductively from the premises of that theory. However, our theorizing also uses both formal and informal empirical data sources as the empirical matters that inspire our problematization of both the reported phenomena and the literature available purportedly 
explaining it (Alvesson and Kärreman, 2007, p. 1265). We rely on our own observations of conceptual modelling practices that we have gathered in many years of field work (e.g., Green et al., 2011; Jabbari Sabegh and Recker, 2017) as an informal source of theorizing (Fiske, 2004). We also rely on published facts and cases of the same practices that inspired us to attempt to provide an explanation of what we believe is a real-world puzzle (Byron and Thatcher, 2016, p. 4) that is only seemingly innocuous: how do analysts and designers interpret multiple models? Noting the observations, we engaged in thought experiments seeking explanations that could satisfy our curiosity (Corley and Gioia, 2011). This paper reports the outcomes from this process.

We proceed as follows: first, we review the background relevant to our theorizing, in particular the available empirical evidence on the use of multiple conceptual models and the available theory base in conceptual modeling research. Then we formulate our new theory and develop its key propositions in three research models. Next, we discuss the scope and contributions of our theory and propose a range of implications.

\section{BACKGROUND}

Two streams of literature inform our theory development. One is the literature that covers the research area of conceptual modeling as a whole. We review this literature first because it helps to position our theory development within the contributions of existing research. Second, we review empirical knowledge on the use of (multiple) conceptual models specifically, because our theory development addresses challenges that stem from an inconsistency between available theoretical knowledge and reported practice when dealing with multiple models. 


\section{Research on conceptual modeling}

Conceptual modeling concerns the development and use of representations of relevant features of a real-world domain that an IS is intended to support (Wand and Weber, 2002). It is an active research area in information systems research with contributions consistently appearing in our top journals (e.g., Parsons, 2011; Recker, 2013; Bera et al., 2014; Clarke et al., 2016; Khatri and Vessey, 2016; Lukyanenko et al., 2017). Two broad research streams can be distinguished: First, there is a stream of research on the design of representations of relevant features of a real-world domain through the use of conceptual modeling grammars and methods. For example, several studies have focused on how a conceptual model can be created, especially how to design a "better" model (e.g., Gemino and Wand, 2005; Shanks et al., 2008; Recker, 2013; Clarke et al., 2016). Studies have also demonstrated how the representation that a conceptual model offers can be augmented through design features like colors (Masri et al., 2008), text (Gemino and Parker, 2009), and other customizations (Samuel et al., 2015). Finally, some studies have examined how practitioners use methods or grammars for the design of conceptual models (Dawson and Swatman, 1999; Purao et al., 2002; Recker et al., 2010).

Second, there is a stream of research on how previously built conceptual models are used for purposes of problem solving or decision making. Much of this research has focused on how users understand a conceptual model in its entirety (Figl et al., 2013; Bera et al., 2014), or various elements within it (Bodart et al., 2001; Parsons, 2011). Fewer studies have focused on how practitioners interpret a conceptual model for specific analysis and design tasks (Bowen et al., 2006; Allen and Parsons, 2010; rFigl and Recker, 2016).

With our theory, we contribute to the second broad stream of research on conceptual modeling. Our explicit focus on multiple models, rather than just one model, is a key extension to the conceptual modeling literature. Common among the studies in either stream is a focus on a 
single artefact - one model or grammar. When studies have employed multiple models or grammars, they were usually compared to evaluate which one was "better".

\section{Empirical evidence on the use of multiple conceptual models}

The starting point for our investigation is an inconsistency between conceptual modeling practice and academic theory. It is common for practitioners to use several conceptual models when analyzing or designing information systems, and they appear to be equipped with some intuition about which models can be combined in purposeful ways. For example, entityrelationship models (Chen, 1976) describe real-world domains in terms of the entities that make up a domain, the attributes that characterize these entities, and the relationships that may exist between the entities. Process models like the Business Process Model and Notation (BPMN, OMG, 2011) describe real-world domains in terms of events that occur and the sequences of activities that are triggered and executed in response to these events. It seems intuitive that entity-relationship models differ from BPMN models: one addresses form and substance, and the other, behavior and change (Burton-Jones and Weber, 2014). It also seems logical that both substance and change are important to understand when one examines what an information system represents and what it is meant to do. This logic is also evident when one considers prominent conceptual modeling methods. For instance, UML features fourteen grammars (and rules for construction) to describe structure, behavior, and interactions of a system from a variety of perspectives (Fowler, 2004). Other longstanding methodologies, such as Multiview (Avison and Wood-Harper, 1986), have promoted multiple models for thirty years.

Not surprisingly in this situation, evidence from both surveys and case studies exists that practitioners indeed often work with multiple models, often constructed with different grammars (Dobing and Parsons, 2008; Petre, 2013; Jabbari Sabegh and Recker, 2017). Moreover, evidence suggests that they do so not to substitute models but to combine them. For example, ninety percent of UML practitioners reportedly work with at least two different models in at least 
a third of their projects, and nearly three-quarters use at least two of the models in two-thirds of their projects (Dobing and Parsons, 2008, p. 6). Similarly, Grossman et al. (2005, p. 393) report that over $60 \%$ of their surveyed UML users worked at least with use case, class, sequence, chart and activity diagrams. Petre (2013) reported that many professional software engineers used UML models selectively and even integrated into their work other models, such as those developed using DFD, ERD, BPMN and other grammars (p. 728). In a similar manner, case studies of model-driven engineering practices illustrate how practitioners use multiple types of models as means of reference and communication during systems development (e.g., Cherubini et al., 2007, p. 561). Other cases detail the issues users encounter when working with multiple models (Baker et al., 2005, pp. 483-487).

Of course, one might believe that the use of multiple models during systems analysis and design is no longer current or relevant, but this assertion seems incorrect. While certainly modern approaches to systems development such as agile have gained popularity (Conboy, 2009), this situation does not mean that model-based systems development practices have disappeared. For example, model-driven engineering is practiced widely in many industries and across organizations both large and small (e.g., Mohagheghi et al., 2013; Hutchinson et al., 2014; Whittle et al., 2014). In these projects, a vast amount of modeling techniques and models is reportedly in use (e.g., Grossman et al., 2005; Petre, 2013). Moreover, a recent interview study in 2017 showed that all interviewed IS practitioners used more than one type of conceptual model in their systems analysis and design tasks (Jabbari Sabegh and Recker, 2017). Clearly, in practice, models developed with various grammars appear to be used in combination. Yet, in the literature, studies with an explicit focus on multiple models are sparse. Table 1 summarizes literature that explicitly focuses on combinations of conceptual models. 


\section{Table 1. Literature on the Use of Combinations of Conceptual Models}

\begin{tabular}{|c|c|c|c|}
\hline Reference & $\begin{array}{l}\text { Object of } \\
\text { study }\end{array}$ & Summary of Research & Implications for This Paper \\
\hline $\begin{array}{l}\text { Kim et al. } \\
(2000)\end{array}$ & $\begin{array}{l}\text { Usability of } \\
\text { multiple } \\
\text { models as part } \\
\text { of a system- } \\
\text { development } \\
\text { methodology }\end{array}$ & $\begin{array}{l}\text { The research examined } \\
\text { representation aids that assist } \\
\text { users in using multiple models to } \\
\text { solve problems during systems } \\
\text { development. It shows that visual } \\
\text { cues and contextual information in } \\
\text { multiple models assist users in } \\
\text { searching for related information } \\
\text { and developing hypotheses about } \\
\text { the target system. }\end{array}$ & $\begin{array}{l}\text { This study proposed an } \\
\text { alternative theory with potential } \\
\text { for conjunction: The study } \\
\text { examined external aids that are } \\
\text { not inherent to the models } \\
\text { themselves and that may } \\
\text { interact with the explanatory } \\
\text { mechanisms we develop. }\end{array}$ \\
\hline $\begin{array}{l}\text { Siau and } \\
\text { Lee }(2004)\end{array}$ & $\begin{array}{l}\text { Interpretation } \\
\text { of class } \\
\text { diagrams and } \\
\text { use case } \\
\text { diagrams in } \\
\text { UML }\end{array}$ & $\begin{array}{l}\text { The research showed that use } \\
\text { case diagrams and class } \\
\text { diagrams depict different aspects } \\
\text { of a problem domain. To users, } \\
\text { the models appear to have very } \\
\text { little overlap in the information } \\
\text { captured, and both are perceived } \\
\text { as necessary in requirements } \\
\text { analysis. }\end{array}$ & $\begin{array}{l}\text { This study suggested two } \\
\text { relevant properties of model } \\
\text { combinations: that they do not } \\
\text { overlap and that they are } \\
\text { complementary. However, the } \\
\text { study did not identify from where } \\
\text { complementarity or overlap in } \\
\text { the models would stem. }\end{array}$ \\
\hline $\begin{array}{l}\text { Dobing and } \\
\text { Parsons } \\
\text { (2008) }\end{array}$ & $\begin{array}{l}\text { Use of UML } \\
\text { diagram types }\end{array}$ & $\begin{array}{l}\text { Modeling practitioners use } \\
\text { multiple types of UML diagrams in } \\
\text { most projects. More than } 50 \% \text { of } \\
\text { users report that they use five or } \\
\text { more types of diagrams in at least } \\
\text { a third of their software } \\
\text { development projects. }\end{array}$ & $\begin{array}{l}\text { This study established the } \\
\text { ecological validity of our theory, } \\
\text { that is, that practitioners use } \\
\text { multiple models in combination. }\end{array}$ \\
\hline $\begin{array}{l}\text { Gemino and } \\
\text { Parker } \\
(2009)\end{array}$ & $\begin{array}{l}\text { Interpretation } \\
\text { of textual use } \\
\text { cases with use } \\
\text { case models }\end{array}$ & $\begin{array}{l}\text { The research shows that } \\
\text { participants who receive } \\
\text { supporting diagrams develop } \\
\text { higher levels of domain } \\
\text { understanding than they did with } \\
\text { a textual use case description } \\
\text { alone. }\end{array}$ & $\begin{array}{l}\text { This study indicated that benefits } \\
\text { may accrue from multiple } \\
\text { models that are redundant: use } \\
\text { case diagrams aided the text by } \\
\text { displaying the same information } \\
\text { in a different way. }\end{array}$ \\
\hline $\begin{array}{l}\text { Jabbari } \\
\text { Sabegh and } \\
\text { Recker } \\
(2017)\end{array}$ & $\begin{array}{l}\text { The use of } \\
\text { multiple } \\
\text { conceptual } \\
\text { models during } \\
\text { systems } \\
\text { analysis and } \\
\text { design }\end{array}$ & $\begin{array}{l}\text { The research interviews } \\
\text { contemporary systems analysis } \\
\text { and design practitioners to } \\
\text { establish how and why multiple } \\
\text { models are used in practice. }\end{array}$ & $\begin{array}{l}\text { This study showed that the use } \\
\text { of multiple models during } \\
\text { systems analysis and design } \\
\text { remains current. It also } \\
\text { suggested that selection and use } \\
\text { of multiple models can be } \\
\text { influenced by many different } \\
\text { factors. However, the study did } \\
\text { not offer a theory to explain the } \\
\text { findings. }\end{array}$ \\
\hline
\end{tabular}

We highlight two main points about the literature summarized in Table 1. On the one hand, the few empirical studies on multiple conceptual models mention findings like: 
- " the information depicted by the two diagram types is sufficiently different and not overlapping" (Siau and Lee, 2004, p. 235);

- "integration of information from the multiple perspectives was indeed necessary to thoroughly understand the business case" (Kim et al., 2000, p. 289); and

- " while the use case diagram does not seem to add new information [...,] [it] helps users better understand sets of use cases" [...] "Use cases augmented with a use case diagram provides a more effective communication of system information than use cases alone" (Gemino and Parker, 2009, p. 15 \& 16).

- "all of our interviewees (15 out of 15) reportedly used more than one type of models in their design and analysis tasks. [...] multiple interrelated models were used to represent different aspects of the system" (Jabbari Sabegh and Recker, 2017, p. 64 \& 66).

These passages make three important points. First, they suggest that multiple models are frequently used (Jabbari Sabegh and Recker, 2017) because a potential benefit of multiple models is that they maximize the amount of information about a real-world domain. Second, this effect is not unequivocal, however, as models have to be "sufficiently different" (Siau and Lee, 2004, p. 235). Third, models that do not contain different, complementary information may still offer benefits (Gemino and Parker, 2009), likely because they establish "correspondence" between the representations (Jabbari Sabegh and Recker, 2017, p. 69).

On the other hand, none of the studies we found provided explanatory mechanisms about these effects that were rooted in the models themselves; none of the research focused on the artefacts. For example, Kim et al. (2000) demonstrated the benefits of external aids for understanding multiple models, such as visual cues to aid the transition between diagrams, or a context diagram to position the relative importance of individual items. There is no theory on 
which attributes that are inherent to conceptual models explain how best to combine them for use.

We draw three primary conclusions from this literature review:

1. There is evidence that suggests that practitioners work with multiple models (Grossman et al., 2005; Dobing and Parsons, 2008; Mohagheghi et al., 2013), and that practitioners prefer having them (Whittle et al., 2014), and obtain benefits from them (Siau and Lee, 2004; Gemino and Parker, 2009). However, we do not yet fully understand how and why that situation is.

2. We do not yet fully understand which properties of the models themselves would make them more or less appropriate for combination.

3. While extant studies have indicated that "representation" aspects or attributes of models may matter, which such property dominates is not completely clear yet.

In the theory development that follows, we develop answers to these challenges. To provide a plausible basis for assumptions we require, we build on representation theory, which was originally formulated by Wand and Weber (1990; 1993; 1995), and which has become a central theory researchers have used to make predictions about conceptual modeling (Moody, 2009; Siau and Rossi, 2011). Because we draw on it extensively, we provide a brief description in Appendix A. A more detailed account of representation theory as it currently stands, its origins and development over time, is provided in Burton-Jones et al. (2017).

\section{THEORY DEVELOPMENT}

In describing the development of our new theory about the interpretation of multiple conceptual models, we follow three main steps (Whetten, 1989; Weber, 2012). First, we introduce the constructs that conceptualize our independent variable: conceptual model combinations. 
Second, we present constructs that conceptualize our main dependent variable: the interpretation of multiple models. Third, we develop propositions that describe the associations between these constructs. Table A1 summarizes relevant construct definitions.

\section{Completeness and Overlap of Conceptual Model Combinations}

We start by illustrating combined ontological completeness and ontological overlap in conceptual models (Figure 1). In Figure 1, the large circle describes a set of real-world phenomena that is to be represented. The representations required to develop a faithful (i.e., clear, complete, and accurate, see Weber, 1997, p. 83) description of these phenomena is indicated by the black dots, which symbolize different ontological constructs required (e.g., which things are of relevance? What are their properties? Which events occur that change the states of these things?). The two shaded circles describe the level of representation of these phenomena achieved in two conceptual models: A and B. Each model provides some, partial, representation of the phenomena, that is, each model has some level of ontological completeness. 


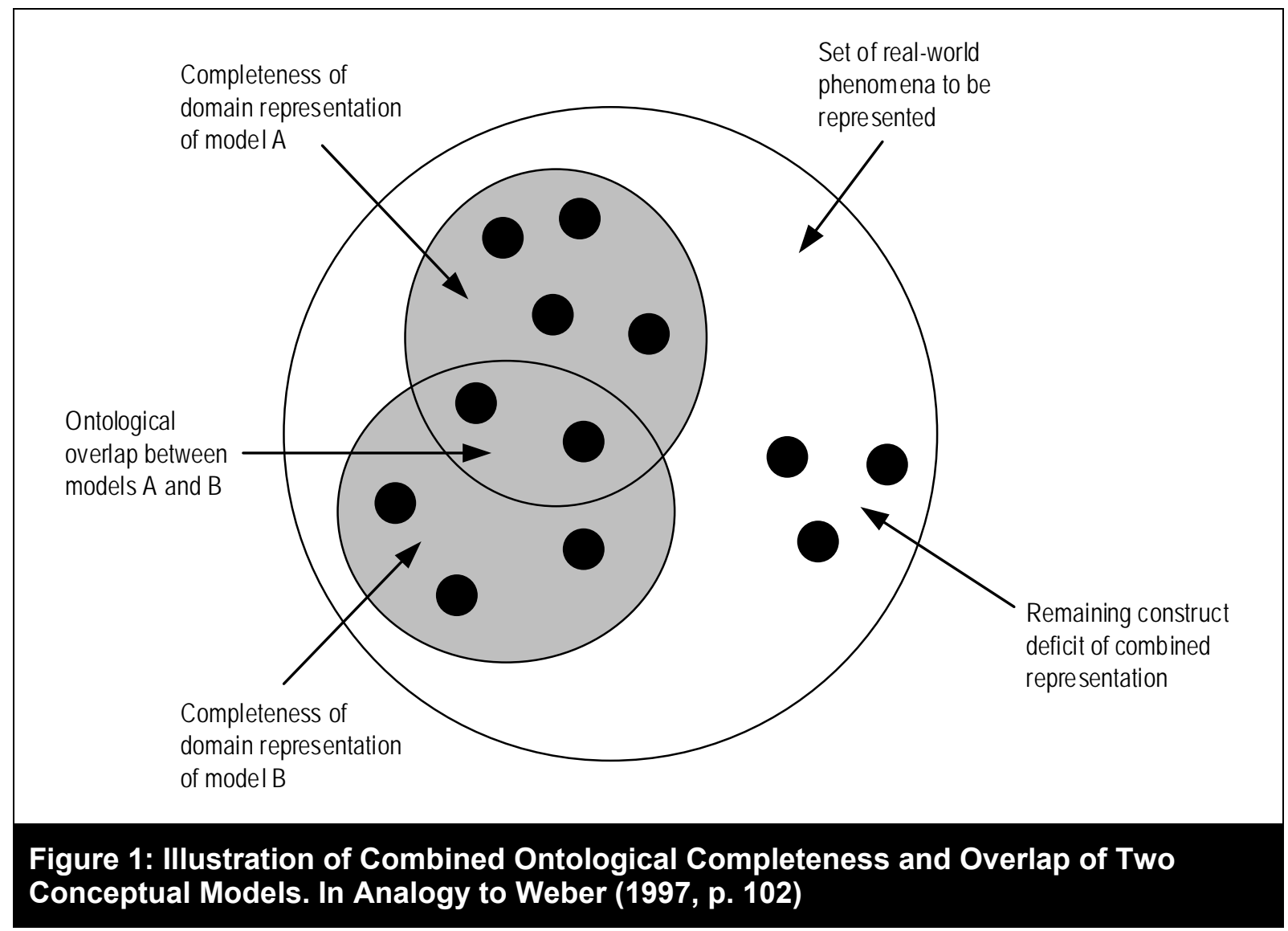

To describe the combination of models (A and B), we define two constructs:

1. Combined ontological completeness: the level of representational coverage a set of multiple models provides about some real-world phenomena. The level of combined ontological completeness is defined as the sum of ontological construct representations available in each of the models (Figure 1).

2. Ontological overlap: the set of redundant representations across a set of models, that is, the extent to which a (partial) representation of some real-world phenomena in one model is already available in another model. The level of ontological overlap is defined as the sum of ontological construct representations shared between the models (Figure 1).

Figure 1 also illustrates the notion of remaining construct deficit, which clarifies the level of combined ontological completeness that is achievable. Models are created using grammars that 
provide constructs that describe the semantics of real-world phenomena. However, because, as detailed in Appendix A, no available conceptual modeling grammar is complete, no single grammar offers constructs to develop a full representation of a real-world phenomena. Therefore, all grammars have a representational limit defined by their extent of construct deficit, which is the maximal ontological completeness (MOC) offered by a grammar. Therefore, any one model is, at best, maximally ontologically complete (but not fully complete). In fact, models are often less than maximally complete, as most do not contain all grammatical constructs only a small subset (zur Muehlen and Recker, 2008). In other words, the actual level of completeness of a conceptual model is often less than its potential level of completeness.

Theoretically, two or more models in combination could achieve a full representation of all required real-world phenomena, but the level of combined ontological completeness depends on selecting models for combination that maximize the completeness of representation. The combined ontological completeness of the models is also constrained by the maximal ontological completeness of the grammars used to create the models: for example, no number of BPMN models, however large, will ever offer a full representation of a real-world domain because the BPMN grammar is ontologically incomplete (Recker et al., 2010).

\section{Interpretation of Conceptual Model Combinations}

Next, we describe the phenomenon that our theory purports to explain: the interpretation of multiple conceptual models.

Interpretation of one or more conceptual models is primarily a task of model readers (sometimes also called model interpreters, see Gemino and Wand, 2004), that is, those users who during analysis and design engage in solving problems and making decisions with the use of previously built conceptual models, as opposed to those who develop conceptual models (i.e., 
model creators or simply modelers, see Gemino and Wand, 2004). ${ }^{1}$ Addressing model readers is important because system failures often stem from communication failures between analysts and users in the early stages of system analysis and design (Lauesen and Vinter, 2001). How do individuals interpret-"read"-conceptual models? The answer to this question is not straightforward. Research has established the purposes of interpreting conceptual models, such as supporting communication between developers and users, helping analysts understand a domain, providing input for systems design processes, and documenting requirements for future reference (Kung and Sølvberg, 1986; Wand and Weber, 2002). It has also examined intended or reported benefits from interpreting conceptual models, such as input to organizational redesign and improved documentation of operational processes (e.g., Indulska et al., 2009). Another set of studies has identified the extent of conceptual model interpretation by practitioners in tasks such as database design and management, software development, business process improvement, or enterprise architecture design (Davies et al., 2006; Fettke, 2009).

These findings demonstrate that the purposes and application areas of conceptual models are varied. However, independent of purpose and application, all uses of conceptual models involves interpreting their content (Burton-Jones and Meso, 2008) - and it remains unclear what interpreting conceptual models as an act involves. Burton-Jones et al. (2009, p. 498) suggest that model interpretation can be examined from two perspectives: interpretational fidelity (how faithfully—viz., completely, clearly and accurately—does the interpretation of one or more conceptual models represent the denotational semantics in the models intended by their creators?) and interpretational efficiency (what resources are used to interpret one or more conceptual models?). While this distinction has been applied widely in the literature to 
distinguish different outcome variables, such as scores on problem solving questions as a measure of interpretational fidelity, or time taken to complete a problem solving task as a measure of interpretational efficiency (e.g., Bodart et al., 2001; Gemino and Wand, 2005; Shanks et al., 2008; Recker and Dreiling, 2011; Bera et al., 2014), it does not elaborate on the act of interpretation per se. We take this step.

We start by suggesting that conceptual model interpretation is a goal-directed activity that involves the user (the subject), the model(s) (the object), and the task (the organizational action that requires the interpretation of one or more conceptual models). We assume that (a) the user is an individual person who interprets a conceptual model for a task ${ }^{2}$, (b) conceptual models are tangible artifacts that provide a representation of a real-world domain that is relevant to the user given a particular task (Wand and Weber, 1990), and (c) the task is a goal-oriented activity, so task outcomes can be compared to predefined task requirements (Zigurs and Buckland, 1998). This definition stresses that interpreting models occurs as part of a particular task, rather than for its own sake- - "just to read them". A task goal might be to identify system requirements from a domain model in order to express relevant functional requirements completely and clearly. Or, a task goal might involve specifying database queries accurately and efficiently, which may require the models to be not only expressive but also parsimonious (Bowen et al., 2006). Task goals may even differ to the point at which incomplete and/or inaccurate conceptual models may be required. Independent from the nature of the task goal, however, model interpretation is inevitably characterized by task goals. Therefore, requirements in regard to the interpretation of one or more conceptual models in support of the task can be defined a priori.

The use of conceptual models can also occur at a group level. To limit the scope of our study, we focus on the individual level in our theory. 
Moreover, in this definition, interpretation of one or more conceptual models is a means to an end, rather than an end in itself. The tasks and task goals against which interpretational fidelity or efficiency must be evaluated may vary, but independent of the specific tasks, the act of interpreting one or more conceptual models always entails at least three components: selection, action, and evaluation. The basis for these components stems from research on cognitive representation and control of action processes (e.g., Beach and Mitchell, 1978; Locke and Latham, 1990): people engage in behavior, driven by a mental representation that links higherlevel goals (such as those imposed by a task) to specific actions (such as the selection of models for reading) that are instrumental in achieving these goals. In doing so, people evaluate the performance expectancy of any object they may use in these actions, perform the actions, and then compare the achieved performance against their expectations. When faced with multiple options (e.g., multiple models), people perform profitability tests to compare acceptable options (Beach and Mitchell, 1978). ${ }^{3}$

Following this line of reasoning, we define the selection, action, and evaluation components of conceptual model interpretation.

\section{Selection: deciding which conceptual models to read}

Prior to engaging in a task in which a user will interpret a set of available conceptual models, the user has expectations about perceived performance gains from reading or studying the conceptual models. These expectations are similar to those ascribed to other artefacts (e.g., built information systems) with which the user plans to engage in a task, such as their ability to

It should be clear from this discussion that we view interpretation of conceptual models as a primarily rational act in which individuals make decisions in choice situations (such as selecting a set of conceptual models for an upcoming task) by recognizing available alternatives and then balancing what they perceive to be costs (such as ontological overlap) and outcomes (such as level of domain understanding) based on individual preference functions (Scott, 2000). 
help the user perform tasks more quickly, improve efficiency, and increase the quality of their work (Venkatesh and Davis, 2000; Brown et al., 2012). When a user has a variety of conceptual models to assist in their model-based task, the user's performance expectancies will determine a profitability test (Beach and Mitchell, 1978) for choosing the most profitable candidate (a specific combination of models from the given set). This test will manifest in a selection decision about which model or model combination to read in an upcoming task. For instance, if an analysis task involves the redesign of an organizational procedure to minimize the use of resources, the user may select models that convey information about workflow processes and role allocations, such as activity charts and swimlane diagrams. On the other hand, if a task involves presenting an overview to senior managers who need to grasp a domain quickly, the user may select models that convey only essential information on a high level of abstraction, such as use case diagrams or class diagrams.

Action: generating domain understanding from the conceptual models

Having selected a conceptual model combination, the user engages in the model-based task and evaluates it in terms of whether and how many performance gains stem from interpreting the conceptual models. Conceptual models can support many tasks (e.g., systems analysis, communication, design, project management, end-user querying, process redesign, organizational change management) (Kung and Sølvberg, 1986; Wand and Weber, 2002; rFigl and Recker, 2016), so defining the performance gains will vary depending on the task. For example, during database design a conceptual model might be interpreted with the goal to identify the constraints required for SQL expressions (Bowen et al., 2006).

In any case, however, conceptual models must be interpreted in order to realize performance gains from them (Aguirre-Urreta and Marakas, 2008, p. 12; Burton-Jones et al., 2009, p. 499). Therefore, for all tasks, the interpretation of conceptual models necessarily and unequivocally involves reading the model to construct knowledge about the depicted domain. Hence, one key 
evaluation of performance gains must be how much domain understanding can be generated from interpreting a conceptual model combination during a task (Gemino and Wand, 2004; Shanks et al., 2008; Burton-Jones et al., 2009; Recker and Dreiling, 2011). Domain understanding is generated when model readers organize and integrate the information presented in the conceptual models with their own experience and mental models (Mayer, 1989), thereby constructing new knowledge about the elements in a real-world domain (surface understanding) and the actual and possible relationships between these elements (deep understanding) (Mayer, 2009). The user then applies this domain understanding in completing the task they set out to do.

\section{Evaluation: appraising the usefulness of the conceptual models}

A key finding of the research on cognitive representation and control of action processes is that people continuously update the mental representations that govern their actions as part of a progressing decision (e.g., Beach and Mitchell, 1978; Beach, 1993). They reflect on the options selected and the action outcomes achieved to evaluate the compatibility between the two. For example, people update their expectations about behaviors (e.g., how they undertake a task) based on their own past behaviors that either confirmed or disconfirmed their previous expectations (Oliver, 1977). The adjusted perceptions then provide the basis for subsequent behaviors (Bem, 1972). In this vein, model readers who employ a conceptual model combination perform a cognitive appraisal, evaluating the performance gains from interpreting the conceptual models for a particular task by reflecting on their expectations that led to the initial profitability test and determining whether their pre-task expectations were confirmed (Oliver, 1977; Recker, 2010). Performance gains from interpreting conceptual models depend on the nature of the task. For instance, one might evaluate whether reading conceptual models during a systems analysis task increased the user's task efficiency (e.g., by comparing task completion times). However, independent of any task-specific performance metric, performance 
gains should also manifest as beliefs about the performance that results from the object in use (Venkatesh et al., 2003), so they can be measured as the perceived usefulness of the chosen conceptual models in supporting the task at hand. In this context, perceived usefulness can be defined as the degree to which a model reader believes that a particular conceptual model combination was effective in achieving the intended task objectives (Davis, 1989; Maes and Poels, 2007).

\section{Proposition Development}

Having described the constructs in our theory, we now develop propositions that describe the associations between the constructs. Figure 2 shows the key associations-the main propositions-we explore in this section. The three variables visualized in the dashed part of Figure 2, viz., environmental uncertainty, task nature and prior domain knowledge, describe possible boundary conditions situated in the conceptual modeling context. We discuss these in Appendix C.

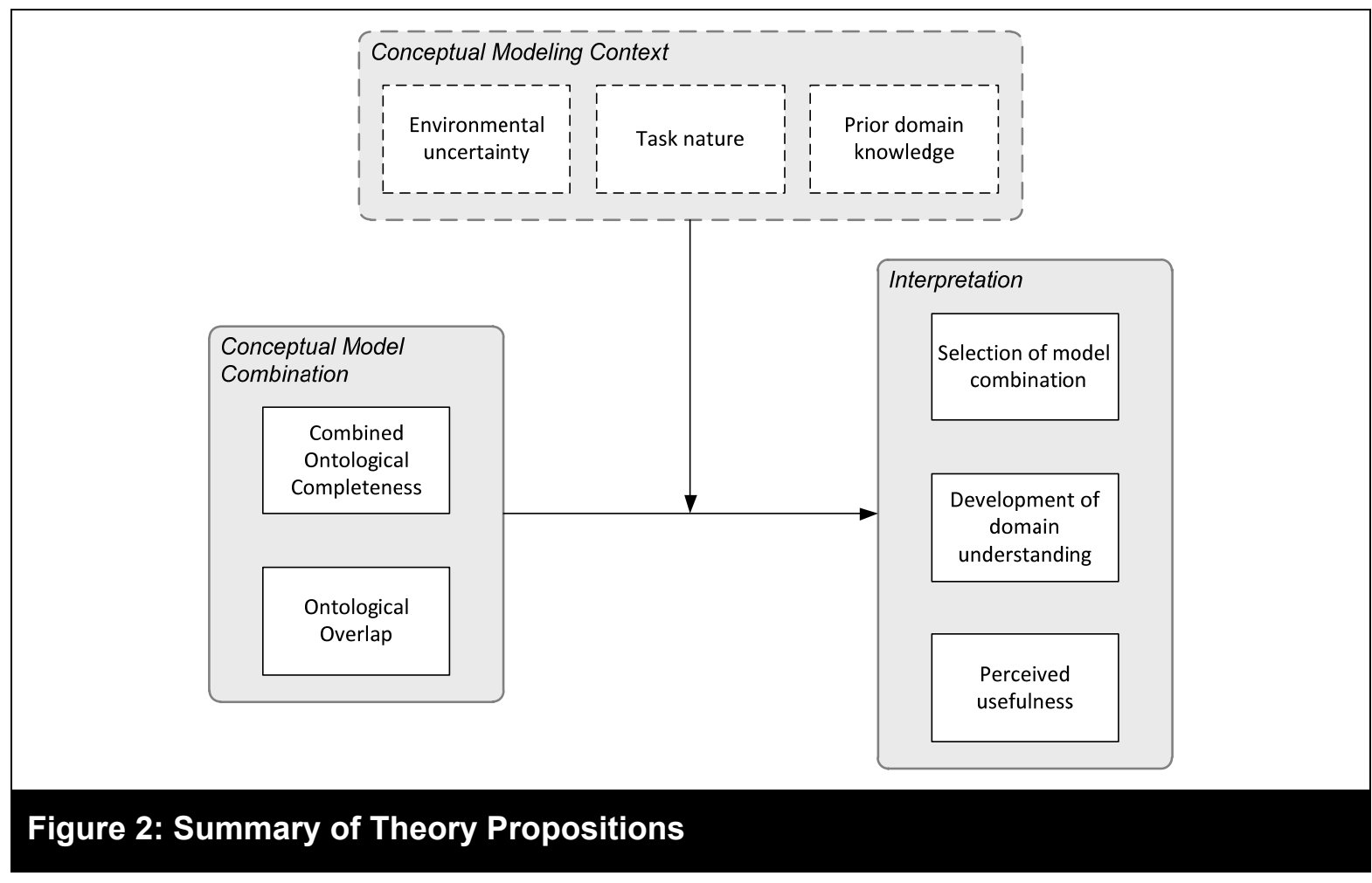




\section{Predicting the selection of conceptual model combinations}

The selection proposition concerns which models from a set of available models with different levels of ontological completeness users will select to complete an upcoming task. Figure 3 illustrates this proposition. It suggests that individuals will start selecting multiple conceptual models if available but only until some point.

The literature on cognitive fit (Vessey and Galletta, 1991; Agarwal et al., 1996; Khatri et al., 2006) suggests that individuals select models to aid their tasks based on a mental model of the problem space they are faced with. For example, for symbolic tasks they would choose a tabular representation of the domain (Vessey and Galletta, 1991). As we have stated earlier, the interpretation of models is likewise characterized by task goals. Specifically, conceptual models aid in the task of requirements analysis for some problem context. However, cognitive fit theory implies that unless the combination of models can represent semantically all the elements of the problem task then the mental representation of the user will be degraded and performance will be degraded.

Therefore, notwithstanding an initial model selection, on the assumption that multiple models about a real-world domain are available to model readers, we predict that, prima facie, individuals will select additional models to complement their initial choice because they desire a maximal level of ontological completeness of the combined representation of some focal realworld problem they are presented with in some task. They do so because any one model will have construct deficit. In other words, if available, users will likely select additional models because they have a desire to compensate for the impoverished representation that any one model provides (see also the discussion of adaptive behaviors by Weber, 1997, pp. 95-96). One typical manifestation of an impoverished representation is a conceptual model that focuses on a particular design dimension (say, data structures) but omits a different dimension (say, system behaviour). Intuitively, these different models each provide a partial level of representation. 
Combining them provides a more complete representation, which appears at face value desirable to a user because by increasing the level of combined ontological completeness of a domain's representation, more information will be available for integration into a mental model of the real-world phenomenon being represented. Therefore, we propose initially:

P1a. Given one conceptual model, users will select additional models for use in their task such that the combined ontological completeness of the model combination will be maximized.

Yet, as visualized in Figure 3, the selection logic will not be linear. At some point, users will stop selecting additional models when they appear, at face value, to convey the same information, even if the additions would provide an increased level of completeness. Our reasoning is as follows:

Selecting additional models increases the chance that the ontological overlap between models will increase. This situation decreases the clarity of the combined representation because several constructs are in the set of models that describe the same real-world phenomenon. This situation may lead to confusion when users inspect the available models: users might wonder why certain constructs appear multiple times and/or might assume that a redundant construct stands for some other type of phenomenon (Weber, 1997, p. 99). In either case, the models will appear "complex." Therefore, to mitigate the anticipated additional effort that is associated with generating understanding from conceptual models, we argue that model users will follow a law of diminishing returns, choosing additional models that maximize the combined ontological completeness only until they reach a level of bearable overlap they can tolerate. Should this level of overlap be exceeded, we predict that users will de-select models, even lowering the combined ontological completeness that can be achieved. Otherwise, the domain representation achieved will be undermined by lack of clarity and it will require too much cognitive load when users interpret the models, as the bearable level of combined ontological 
overlap is constrained by users' cognitive processing capacity (Miller, 1956). Because of their limited overall cognitive capacity, users do not refer to the entire set of models at once as a single chunk of information (Ward and Sweller, 1990). Instead they screen each model for local information and thus they can anticipate the cognitive demands of information processing very quickly. Therefore, users will not select additional models even if adding another model would increase combined ontological completeness. We propose:

P1b. Users will select additional models for use in their tasks only until their bearable level of ontological overlap of the combined representation is reached.

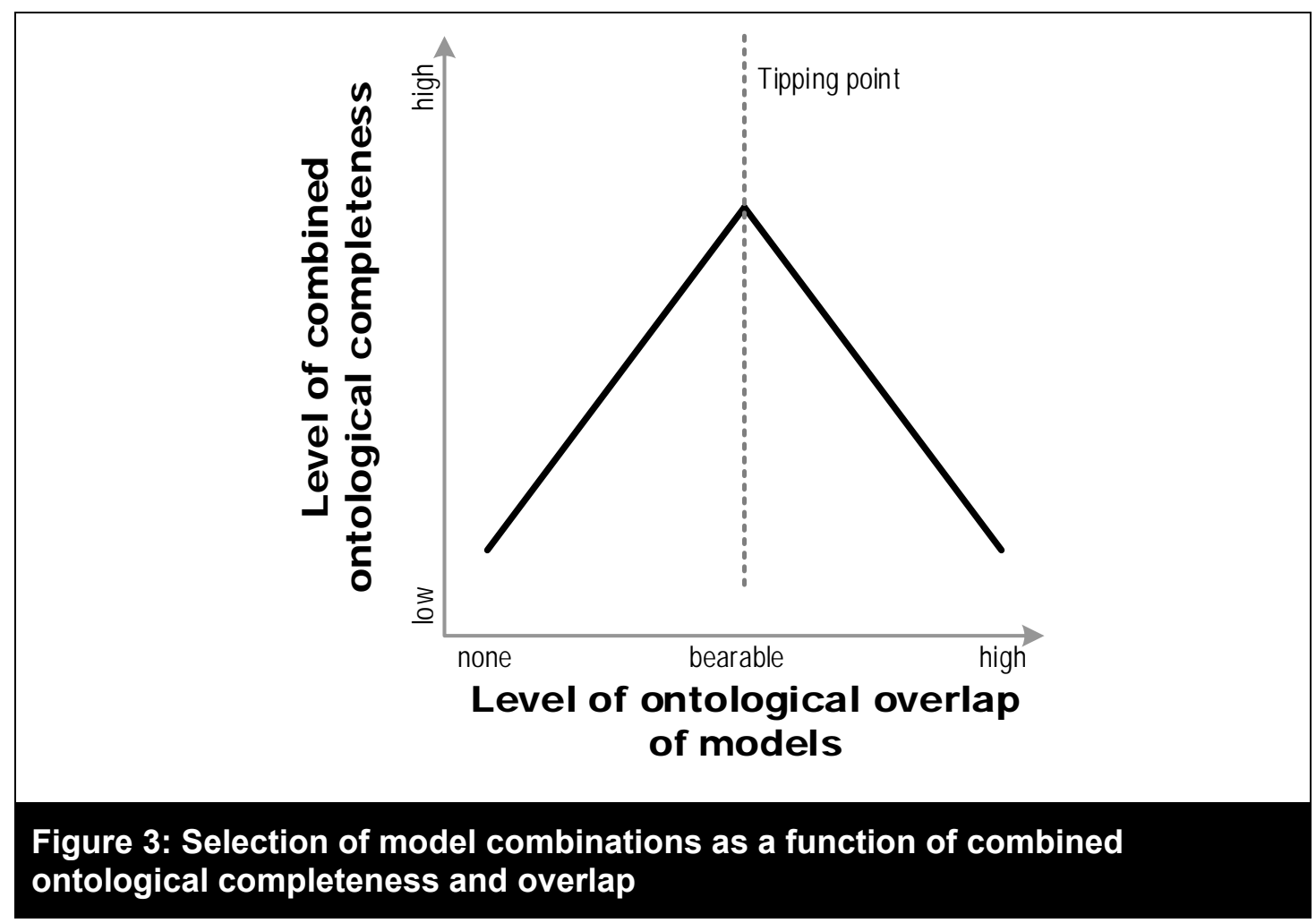

Predicting the development of domain understanding from conceptual model combinations

The domain understanding proposition concerns which model combinations maximize model readers' ability to gain understanding about the real-world domain represented during their interpretation. Figure 4 illustrates this proposition. 
When reading models, users create a mental model representation of the domain based on the information the models provide (Gemino and Wand, 2005). They identify and internalize constructs in the model by integrating them with concepts in their mental representations of the domain (Mayer, 1989; Pretz et al., 2003), thereby updating their existing knowledge and constructing new knowledge. A complete mental representation of the domain is a key driver of a user's ability to reason about the domain in the course of problem solving (Newell and Simon, 1972).

When interpreting conceptual models, the construct deficit that is inherent in any single model is a noted issue: users lack relevant information about a real-world domain, which diminishes the level of understanding about a phenomenon a user can generate (e.g., Bajaj, 2004; Parsons, 2011). However, a combination of models provides more representation elements that convey meaning about the phenomenon in a real-world domain when the combination has higher ontological completeness than any one model alone. If such is the case, more information is available for assimilation into users' mental representation about the phenomenon, improving the level of domain understanding that can be gained from the models. Therefore, we state:

P2a. Model users who read a combination of models that have a high level of combined ontological completeness will generate higher levels of domain understanding than will users who read a combination of models that have a low level of combined ontological completeness.

The level of domain understanding that can be achieved from a selected set of models is moderated by the level of ontological overlap between the models. Model combinations with higher levels of ontological overlap introduce additional extraneous cognitive load (Sweller, 1988; Gemino and Wand, 2005) in two ways: (1) Model users must identify the overlapping constructs. Identifying redundant constructs complicates readers' cognitive search process (i.e., the process of locating visual constructs in a model and identifying relevant attributes and 
relationships) (Larkin and Simon, 1987). (2) Model users must reconcile their meaning, which adds complexity because users have to compare the semantics of constructs. The heightened cognitive demand to understand redundant constructs across models diminishes the capacity to absorb information and hence the ability to generate domain understanding. Therefore, we argue that:

P2b. The positive impact of combined ontological completeness of model combinations on users' ability to gain domain understanding decreases as the ontological overlap in the combination of models increases.

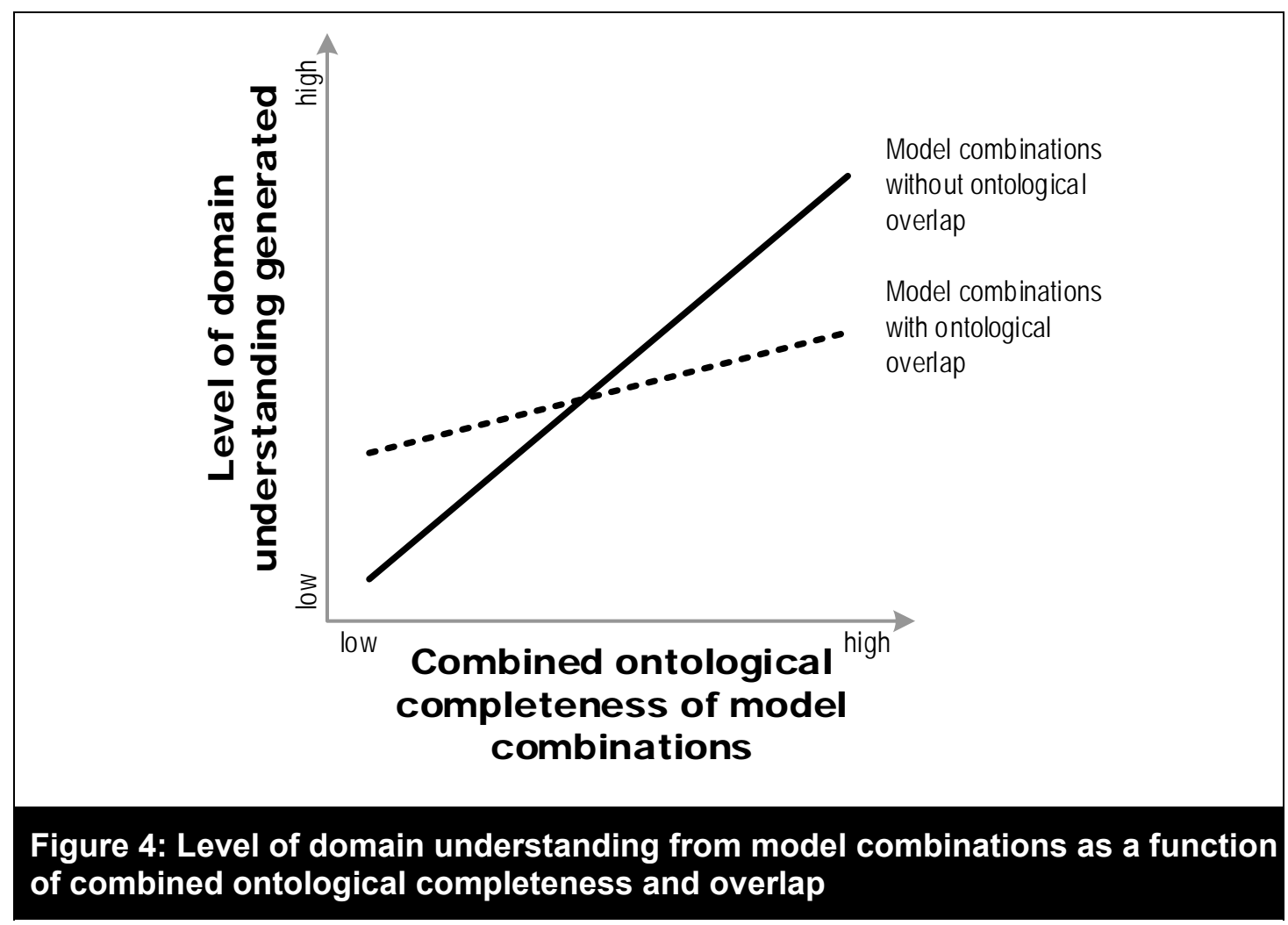

Predicting the perceived usefulness of conceptual model combinations

Our third proposition concerns model users' evaluation of performance gains from interpreting multiple models. Figure 5 illustrates this proposition. 
We predict that users' perceptions of model combinations' usefulness will be more positive when the representation's combined ontological completeness is high. Perceived usefulness can be understood as the degree to which a person believes that a particular model is effective in achieving the intended task objectives (Davis, 1989; Recker et al., 2011). Evaluations of the usefulness of conceptual models for a task depend on users' having the necessary and sufficient manifestations of relevant real-world phenomena explicit in a model. If there are deficits in the desired representations, the available representation will be less effective as a way to solve problems (Gemino and Wand, 2004). Therefore, users are unlikely to find multiple models with impoverished quality useful (Lindland et al., 1994; Maes and Poels, 2007). We state:

P3a. Users perceive a combination of models with a high level of combined ontological completeness as more useful in model-interpretation tasks than a combination of models with a lower level of combined ontological completeness.

However, model combinations with increased ontological completeness and increased ontological overlap will be evaluated as less useful because the additional complexity of the representation will offset the gains in representational effectiveness by requiring more cognitive effort to reconcile the meaning conveyed (Wand and Weber, 1993). Ontologically overlapping models add confusion, which adds complexity to the task users set out to complete. As the extent of overlap increases, the perceived usefulness of the combination decreases. A clear (i.e., non-overlapping) interpretation of conceptual models will allow a user to glean meaning from the models more easily and, thus, retain cognitive capacity to complete the task at hand. Conversely, if additional effort must be invested in interpreting the models because of high overlap, less capacity is available for the problem-solving task. Such perceptions of effort will undermine the perception of usefulness (Recker, 2010). We expect that the detrimental impact of ontological overlap on perceived usefulness is stronger than the positive impact of ontological 
completeness. Users deem parsimonious models more useful for their tasks than complete and complex representations because of the computational advantage parsimonious models provide in information processing (Larkin and Simon, 1987):

P3b. Users' perceptions of the usefulness of conceptual model combinations decreases as the level of ontological overlap of the combinations increases, such that the negative effect of ontological overlap is stronger than the positive effect of combined ontological completeness.

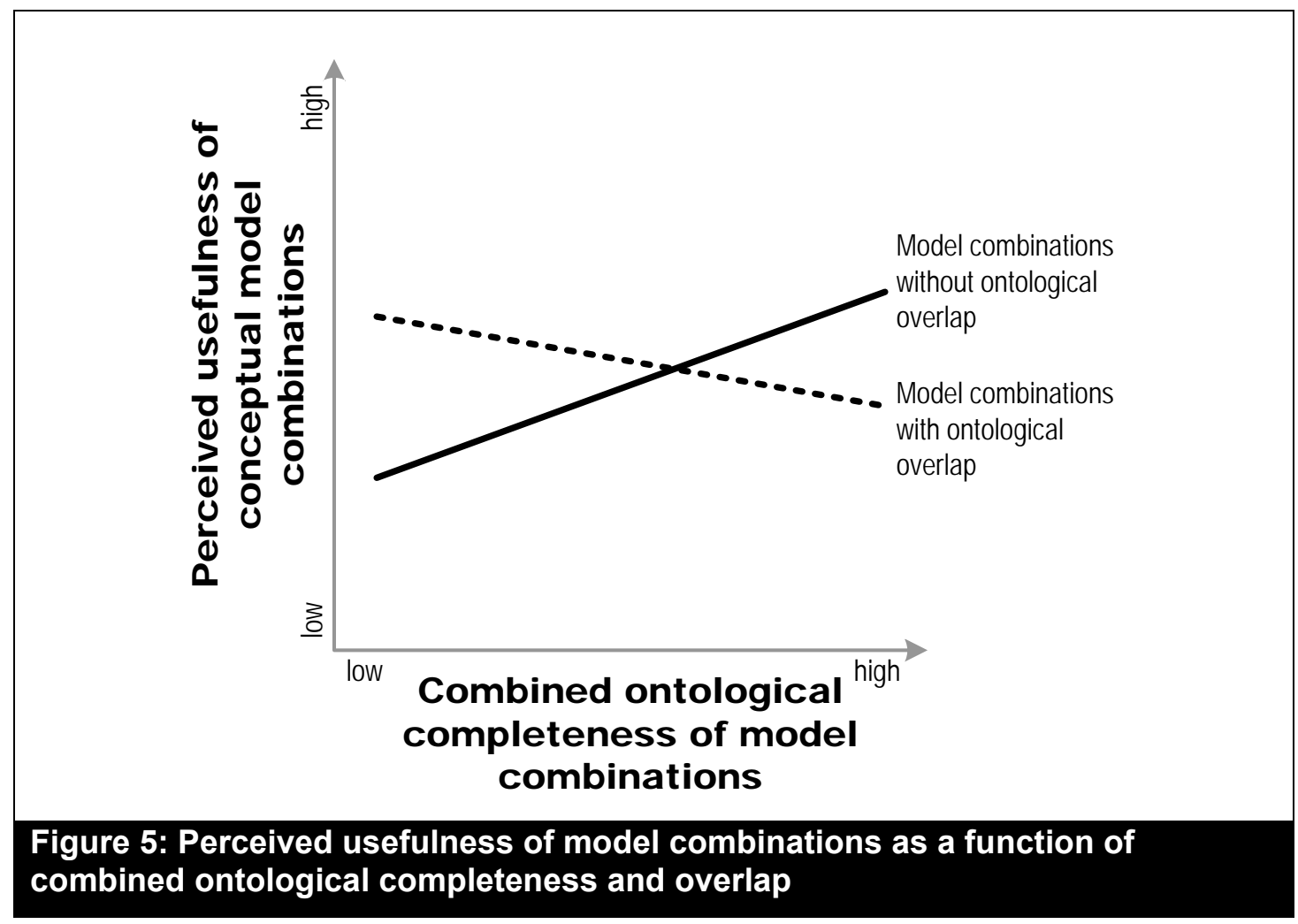

\section{DISCUSSION}

\section{Summary of the Scope and Contributions of our Theory}

We developed new theory about how individuals interpret multiple conceptual models, which posits that two attributes of model combinations, combined ontological completeness and 
ontological overlap, are key determinants for their selection, understanding, and perceived usefulness by users.

Having done so, we feel it is prudent to delineate the boundary conditions of our theorizing. We start by identifying the scope of our theory as limited by its assumptions. We developed a specific theory (how users interpret multiple models) from Wand and Weber's (1995) more general theory of information systems as representations. Therefore, like their work, our theorizing describes a model of the artefacts that define an information system's deep structure. As such, it focuses on the semantics of conceptual models and grammars (Bera et al., 2014; Clarke et al., 2016). The choice of visual syntax (e.g., a rectangle or a circle, Moody, 2009) is not part of our theory. Also, our theory does not describe in detail the psychological, linguistic, or cognitive processes through which users engage with conceptual models to understand realworld domains (Truex and Baskerville, 1998; Evermann, 2005). In addition, it does not address pragmatic factors (e.g., tasks, knowledge, external conditions) that would describe their use. However, as we discuss in Appendix C, such factors can be brought into the theory's focus. A second boundary to the scope of our theory stems from its position in the stream of conceptual modeling literature. Our theory is about the selection and interpretation of combinations of previously built conceptual models by practitioners in analysing and understanding systems requirements. It is not a theory of conceptual model creation even though we believe design principles could possibly be derived from our explanations. It is also not a theory of the use of methods and grammars for the design of conceptual models (Purao et al., 2002).

Third, our theory of model interpretation bears some resemblance to theories of information behaviour in general because it conceptualizes some specific aspect of "how people need, seek, manage, give and use information in different contexts" (Fisher et al., 2005, p. xix). However, with its focus on the role of models as representations of an information system's 
deep structure (Wand and Weber, 1995; Burton-Jones et al., 2017) it is both much narrower than general models of information seeking (e.g., Leckie, 2005) or acquiring (e.g., Rioux, 2005), and more specific in that it focuses on artefacts more so than a person's information-seeking behavior (e.g., Wilson, 1999, p. 251).

Finally, our theory is also bounded because its predictions have not yet been tested. Describing operationalization and measurement strategies for our theory in full would require an entire paper. However, to motivate and guide potential future empirical research to evaluate, refute, extend or otherwise improve our theory, we provide two aids about how empirical research procedures could be carried out. First, in Appendix B we provide an illustration of how our theory can be applied to the analysis of multiple available models presented to an individual. Second, in Appendix C, we provide a discussion of what we believe might be important moderator variables (Figure 2) that should be included in an empirical research design used to test our theory.

In evaluating the contributions our new theory offers, we consider the knowledge provided by the extant representation theory on which it is founded and the empirical research program it has supported to date. Our theory development may be construed as "dropping the theoretical tools, holding the concepts lightly and updating them frequently" (Holmström and Truex, 2011), which can best be explained by considering the two principles of maximal ontological completeness (MOC) and minimal ontological overlap (MOO). We adapted these principles from Green et al. $(2007 ; 2011)$ and Weber $(1997)$ by transferring their application from grammars to models and from model design to model interpretation. This adaptation is "interesting" (Davis, 1971) because it highlights twotensions to the original concepts:

1. The tension between ontological completeness and overlap. We started our theorizing by appropriating two established concepts: MOC and MOO (e.g., Green et al., 2007; Green et al., 2011). In what followed, our theorizing highlighted a potential conflict between these 
two notions that has not been surfaced explicitly earlier. Our theory suggests that, sometimes, combined ontological completeness and ontological overlap may conflict. For instance, imagine a set of models that together maximizes the representation of real-world phenomena and also shares a large set of common representational constructs; viz., the combination has high levels of combined ontological completeness and overlap. Then imagine a second model combination that has a lower level of combined ontological completeness but also a lower level of ontological overlap. Which of these two combinations should be selected, interpreted, and deemed more useful? This question is far from trivial. Green et al. (2011) argued that the primary principle for grammar selection as part of model design should be MOC, but whether that is true for the selection and interpretation of models remains in question. Could model interpretation be governed by principles of clarity (i.e., minimizing construct overload and/or redundancy) over completeness? There is some evidence that suggests that the simplicity of a representation may be more useful than its completeness. For instance, Siau and Lee (2004) showed that users preferred diagrams that were easier to use and that such diagrams enabled them to obtain a more complete representation. Samuel et al. (2015) also demonstrated that practitioners often rationalized the volume of information in models to achieve a simpler, not fuller, understanding of the relevant domain.

2. The tension between model design and interpretation: Weber (1997) and Green et al. $(2007 ; 2011)$ argued that MOC and MOO are criteria that guide designers in their choice of grammars for model creation. We developed a theory for the choice of models for model interpretation, but the relationship between design choices made in the creation of models and the interpretation choices available for a user is an important one. For readers of conceptual models, it is not the grammar and its potential maximal coverage of real-world phenomena that matters but the actual maximal coverage of real-world phenomena that is 
available in any combination of models produced by a grammar or grammars. A model's actual maximal coverage is limited by the number and type of constructs in a grammar, so a model designer has potentially unlimited choices from which to create a complete and clear representation of a real-world phenomenon: they may choose from available or recommended grammars, may opt to use an alternative like free text or additional documents adjacent to the models (Green et al., 2011), or may even alter construct semantics or invent new semantics (Recker et al., 2010). These design choices are not available to these models' readers, who seek to obtain a complete and clear interpretation of a focal real-world phenomenon. One key difference is that model designers should be able to create representations that have a full level of ontological completeness, whereas, provided multiple models are available, model readers can, at best, select a maximally (not necessarily fully) ontologically complete representation.

The questions about the opposition of $\mathrm{MOC}$ and $\mathrm{MOO}$ and the correlation of design and interpretation ultimately require empirical work to resolve. Our theory offers an explanatory logic to guide such work and identifies some of the conditions under which the relationship between MOC and MOO can be examined. Further, Appendix $\mathrm{C}$ introduces three moderator variables that may be useful to identify contexts in which the relationship between MOC and MOO differ.

Our new theory also contributes in several ways to the broader literature on conceptual modeling. This theory is the first model to analyze and explain the interpretation of conceptual models in combinations. Unlike empirical accounts of the use of conceptual models broadly (Dobing and Parsons, 2008; Petre, 2013; Jabbari Sabegh and Recker, 2017), our theory offers principles about how and why users might select different sets of conceptual models to complete their tasks, how much domain understanding they might generate, and how useful they perceive sets of models to be. Also, our theory focuses on the artefacts (viz., the models) themselves. 


\section{Implications for Research}

As the focus of this paper is theory development, the implications of our research relate primarily to future research that enacts or evaluates our theory through empirical research. We see several ways in which our theory can be advanced.

First, our three research models suggest the presence of limits and thresholds. For example, proposition 1 argues that users will select additional models until they reach a bearable level of ontological overlap that is constrained by users' cognitive processing capability. However, users' processing capability is both volatile and contextual (Gobet and Clarkson, 2004); therefore, our theory has no basis on which to speculate ex ante what the thresholds will be for different users, so we cannot offer a hypothesis on this element of the proposition. Instead, the existence and level of the threshold is an empirical question.

Second, the range of predictions could be extended beyond the three core evaluations on which we focus. A promising direction is to develop predictions about the design of model combinations, rather than their interpretation.

A third direction flows from a broader examination of the tasks and the associated goals for the models interpreted during these tasks. We focused on the development of domain understanding because any subsequent interpretation of a model for other analysis and design tasks (say, software specification versus system configuration versus process re-design) depends ultimately on how well individuals can understand the modeled domain (Burton-Jones and Meso, 2008). Still, similar to existing research on using conceptual models for specific tasks, such as the development of database queries (Bowen et al., 2006), it would be useful to see how model combinations could assist different kinds of specific problem-solving tasks.

Fourth, we see a promising research direction in the development of appropriate measurements for our theory. For example, because users evaluate grammars differently based on their 
perceptions of the grammars' ontological completeness and clarity (Recker et al., 2011), it will be important to clarify how a set of models' perceived level of completeness and clarity affect their evaluations and the behaviors of the users who read them. We focused on perceived usefulness as a performance-evaluation metric because it is a well-established measure in the literature. Other suitable metrics include the perceived semantic quality of model combinations (Maes and Poels, 2007) and satisfaction with models (Nolte et al., 2016), to name just two.

Fifth, our theory focuses on attributes of models as artifacts. These can be brought in combination with other elements (e.g., factors that describe the context of conceptual model interpretation) to account for variations in its predictions. We provide a brief discussion of three context factors in Appendix C. A more comprehensive analysis of the context will benefit from programmatic efforts and it could build on Wand and Weber's (2002) taxonomy of context factors.

\section{Implications for Practice}

Two principal implications for practice emerge from our theory. First, we developed theoretical models that can explain and guide choices available to conceptual models' end users when they seek to interpret these models during systems analysis and design tasks. Our theory suggests that two guiding principles—combined ontological completeness and ontological overlapinform the selection, understanding, and usefulness of multiple models. In essence, our theory suggests that model readers should be mindful of whether they require a parsimonious or a complete representation of the real world to complete their tasks effectively.

A second implication arises about the design of multiple conceptual models. We assumed that the purpose for creating conceptual models is to create faithful (i.e., complete, clear, and accurate) representations of a real-world domain. However, as we discuss in Appendix C, under some conditions, such as environmental uncertainty, when working with explorative tasks that involve conceptual model use, or when designing models for users with very high or very low 
domain knowledge, tradeoffs between completeness and clarity may have to be taken into account already during model design, in order to make the created models fit for interpretation. For example, designers may wish to create partially redundant representations to maximize combined ontological completeness at the expense of ontological overlap or, conversely, create representationally deficient conceptual models in order to maximize clarity and simplicity. However, given our focus on model interpretation rather than creation, we have not studied these implications, so they require further testing.

\section{Limitations}

We acknowledge two important limitations. First, we reported on theory development void of any systematic empirical data collection or evaluation. Our suggested logic and explanations thus remain speculative until empirical work is performed. To invite and guide such work, we provide in Appendix B an illustration of procedures for enacting our theory. In Appendix C, we discuss several important boundary conditions that might be relevant to empirical study design. We hope through these means it becomes clear how an empirical analysis of practitioners' interpretation of multiple models could be carried out.

Second, we wish to acknowledge the subjectivity of interpretation mappings that are required in ontological analyses of grammar constructs in conceptual models (Rosemann et al., 2009). As we illustrate in Appendix B, potential interpretation bias can be mitigated in two ways: similar to Recker et al. (2009), the starting point should be the literature on published analyses of the grammars used in the models. Then, like us, researchers should engage in an iterative process based on principles of dialogical reasoning and suspicion (Klein and Myers, 1999) in which interpretation mapping drafts are formulated between multiple researchers who then question each of the suggested mappings, iterating between these two steps to tease out biases and distortions in constructing a jointly agreed result such as that shown in Table B1. 


\section{CONCLUSION}

Systems analysis and design practitioners often work with multiple conceptual models, rather than just one. We proposed a theory that can be used to examine which combinations of conceptual models are likely more suitable for interpretation by model readers. Our theory offers fellow scholars a way to generate more research on conceptual modeling as a theory-in-use and, in turn, increase the relevance of this important traditional stream of IS research. Our own work will test our theory empirically and refine it, and we hope that fellow scholars will join us in this endeavor.

\section{REFERENCES}

Agarwal, R., A. P. Sinha, and M. Tanniru (1996) "Cognitive Fit in Requirements Modeling: A Study of Object and Process Methodologies", Journal of Management Information Systems (13)2, pp. 137-162

Aguirre-Urreta, M. I. and G. M. Marakas (2008) "Comparing Conceptual Modeling Techniques: A Critical Review of the EER vs. OO Empirical Literature", The DATA BASE for Advances in Information Systems (39)2, pp. 9-32

Alexander, P. A. (1992) "Domain Knowledge: Evolving Themes and Emerging Concerns", Educational Psychologist (27)1, pp. 33-51

Allen, G. and J. Parsons (2010) "Is Query Reuse Potentially Harmful? Anchoring and Adjustment in Adapting Existing Database Queries", Information Systems Research (21) 1 , pp. $56-77$

Alvesson, M. and D. Kärreman (2007) "Constructing Mystery: Empirical Matters in Theory Development", Academy of Management Review (32)4, pp. 1265-1281

Avison, D. E. and A. T. Wood-Harper (1986) "Multiview - An Exploration in Information Systems Development", Australian Computer Journal (18)4, pp. 174-179

Bajaj, A. (2004) "The Effect Of the Number of Concepts On the Readability of Schemas: An Empirical Study With Data Models", Requirements Engineering (9)4, pp. 261-270

Baker, P., S. Loh, and F. Weil (2005) "Model-Driven Engineering in a Large Industrial Context - Motorola Case Study", in Briand, L. and C. Williams (eds.) Model Driven Engineering Languages and Systems - MoDELS 2005, Montego Bay, Jamaica: Springer, pp. 476491

Beach, L. R. (1993) "Image Theory: an Alternative to Normative Decision Theory", Advances in Consumer Research (20)1, pp. 235-238

Beach, L. R. and T. R. Mitchell (1978) "A Contingency Model for the Selection of Decision Strategies", Academy of Management Review (3)3, pp. 439-449

Bem, D. J. (1972) "Self Perception Theory", in Berkowitz, L. (ed.) Advances in Experimental Social Psychology, New York, New York: Academic Press, pp. 1-62 
Bera, P., A. Burton-Jones, and Y. Wand (2011) "Guidelines for Designing Visual Ontologies to Support Knowledge Identification", MIS Quarterly (35)4, pp. 883-908

Bera, P., A. Burton-Jones, and Y. Wand (2014) "How Semantics and Pragmatics Interact in Understanding Conceptual Models", Information Systems Research (25)2, pp. 401-419

Bodart, F., A. Patel, M. Sim, and R. Weber (2001) "Should Optional Properties Be Used in Conceptual Modelling? A Theory and Three Empirical Tests", Information Systems Research (12)4, pp. 384-405

Bowen, P. L., R. A. O'Farrell, and F. Rohde (2006) "Analysis of Competing Data Structures: Does Ontological Clarity Produce Better End User Query Performance", Journal of the Association for Information Systems (7)8, pp. 514-544

Brown, S. A., V. Venkatesh, and S. Goyal (2012) "Expectation Confirmation in Technology Use", Information Systems Research (23)2, pp. 474-487

Bunge, M. A. (1977) Treatise on Basic Philosophy Volume 3: Ontology I - The Furniture of the World, Dordrecht, The Netherlands: Kluwer Academic Publishers

Bunge, M. A. (1979) Treatise on Basic Philosophy Volume 4: Ontology II - A World of Systems, Dordrecht, The Netherlands: Kluwer Academic Publishers

Burton-Jones, A. and P. Meso (2008) "The Effects of Decomposition Quality and Multiple Forms of Information on Novices' Understanding of a Domain from a Conceptual Model", Journal of the Association for Information Systems (9)12, pp. 784-802

Burton-Jones, A., J. Recker, M. Indulska, P. Green, and R. Weber (2017) "Assessing Representation Theory with a Framework for Pursuing Success and Failure", MIS Quarterly (41)4, pp. 1307-1333

Burton-Jones, A., Y. Wand, and R. Weber (2009) "Guidelines for Empirical Evaluations of Conceptual Modeling Grammars", Journal of the Association for Information Systems (10)6, pp. 495-532

Burton-Jones, A. and R. Weber (2014) "Building Conceptual Modeling on the Foundation of Ontology", in Topi, H. and A. Tucker (eds.) Computing Handbook, Third Edition: Information Systems and Information Technology, Boca Raton, Florida: CRC Press, pp. 15-1-15-24

Byron, K. and S. M. B. Thatcher (2016) "Editors' Comments: "What I Know Now That I Wish I Knew Then"-Teaching Theory and Theory Building", Academy of Management Review (41)1, pp. 1-8

Chandler, P. and J. Sweller (1991) "Cognitive Load Theory and the Format of Instruction", Cognition and Instruction (8)4, pp. 293-332

Chen, P. P.-S. (1976) "The Entity Relationship Model - Toward a Unified View of Data", ACM Transactions on Database Systems (1)1, pp. 9-36

Cherubini, M., G. Venolia, R. DeLine, and A. J. Ko (2007) "Let's Go to the Whiteboard: How and Why Software Developers Use Drawings", in SIGCHI Conference on Human Factors in Computing Systems, San Jose, California: ACM, pp. 557-566

Clarke, R., A. Burton-Jones, and R. Weber (2016) "On the Ontological Quality and Logical Quality of Conceptual-Modeling Grammars: The Need for a Dual Perspective", Information Systems Research (27)2, pp. 365-382

Conboy, K. (2009) "Agility from First Principles: Reconstructing the Concept of Agility in Information Systems Development", Information Systems Research (20)3, pp. 329-354

Corley, K. G. and D. A. Gioia (2011) "Building Theory about Theory Building: What Constitutes a Theoretical Contribution?", Academy of Management Review (38)1, pp. 12-32

Davies, I., P. Green, M. Rosemann, M. Indulska, and S. Gallo (2006) "How do Practitioners Use Conceptual Modeling in Practice?", Data \& Knowledge Engineering (58)3, pp. 358-380

Davis, F. D. (1989) "Perceived Usefulness, Perceived Ease of Use, and User Acceptance of Information Technology", MIS Quarterly (13)3, pp. 319-340 
Davis, M. S. (1971) "That's Interesting: Towards a Phenomenology of Sociology and a Sociology of Phenomenology", Philosophy of the Social Sciences (1)4, pp. 309-344

Dawson, L. and P. Swatman (1999) "The Use of Object-oriented Models in Requirements Engineering: A Field Study", 20th International Conference on Information Systems, Charlotte, North Carolina: Association for Information Systems, pp. 260-273

Dess, G. G. and D. W. Beard (1984) "Dimensions of Organizational Task Environments", Administrative Science Quarterly (29)1, pp. 52-73

Dobing, B. and J. Parsons (2008) "Dimensions of UML Diagram Use: A Survey of Practitioners", Journal of Database Management (19)1, pp. 1-18

Edwards, J. R. and J. W. Berry (2010) "The Presence of Something or the Absence of Nothing: Increasing Theoretical Precision in Management Research", Organizational Research Methods (13)4, pp. 668-689

Erickson, J., K. Lyytinen, and K. Siau (2005) "Agile Modeling, Agile Software Development, and Extreme Programming: The State of Research", Journal of Database Management (16)4, pp. 88-100

Evermann, J. (2005) "Towards a Cognitive Foundation for Knowledge Representation", Information Systems Journal (15)2, pp. 147-178

Evermann, J. and Y. Wand (2006) "Ontological Modeling Rules for UML: An Empirical Assessment", Journal of Computer Information Systems (46)5, pp. 14-29

Fettke, P. (2009) "How Conceptual Modeling Is Used", Communications of the Association for Information Systems (25)43, pp. 571-592

Fickinger, T. and J. Recker (2013) "Construct Redundancy In Process Modelling Grammars: Improving The Explanatory Power Of Ontological Analysis", in 21st European Conference on Information Systems, Utrecht, The Netherlands: Association for Information Systems,

Figl, K., J. Mendling, and M. Strembeck (2013) "The Influence of Notational Deficiencies on Process Model Comprehension", Journal of the Association for Information Systems (14)6, pp. 312-338

Fisher, K. E., S. Erdelez, and L. McKechnie (2005) Theories of Information Behavior, Medford, New Jersey: Information Today

Fiske, S. T. (2004) "Mind the Gap: In Praise of Informal Sources of Formal Theory", Personality and Social Psychology Review (8)2, pp. 132-137

Fowler, M. (2004) UML Distilled: A Brief Guide To The Standard Object Modelling Language, 3rd edition, Boston, Massachusetts: Addison-Wesley Longman

Fowler, M. and J. Highsmith (2001) "The Agile Manifesto", Software Development (9)8, pp. 2832

Gemino, A. and D. C. Parker (2009) "Use Case Diagrams in Support of Use Case Modeling: Deriving Understanding from the Picture", Journal of Database Management (20)1, pp. 1-24

Gemino, A. and Y. Wand (2004) "A Framework for Empirical Evaluation of Conceptual Modeling Techniques", Requirements Engineering (9)4, pp. 248-260

Gemino, A. and Y. Wand (2005) "Complexity and Clarity in Conceptual Modeling: Comparison of Mandatory and Optional Properties", Data \& Knowledge Engineering (55)3, pp. 301326

Gobet, F. and G. Clarkson (2004) "Chunks in Expert Memory: Evidence for the Magical Number Four ... or is it Two?", Memory (12)6, pp. 732-747

Gray, P. H. and W. H. Cooper (2010) "Pursuing Failure", Organizational Research Methods (13)4, pp. 620-643

Green, P. (1996) An Ontological Analysis of ISAD Grammars in Upper CASE Tools, Unpublished PhD Thesis, Brisbane, Australia: The University of Queensland 
Green, P. and M. Rosemann (2001) "Ontological Analysis of Integrated Process Models: Testing Hypotheses", Australasian Journal of Information Systems (9)1, pp. 30-38

Green, P., M. Rosemann, M. Indulska, and C. Manning (2007) "Candidate Interoperability Standards: An Ontological Overlap Analysis", Data \& Knowledge Engineering (62)2, pp. 274-291

Green, P., M. Rosemann, M. Indulska, and J. Recker (2011) "Complementary Use of Modeling Grammars", Scandinavian Journal of Information Systems (23)1, pp. 59-86

Gregor, S. (2006) "The Nature of Theory in Information Systems", MIS Quarterly (30)3, pp. 611642

Grossman, M., J. E. Aronson, and R. V. McCarthy (2005) "Does UML Make the Grade? Insights from the Software Development Community", Information and Software Technology (47)6, pp. 383-397

Holmström, J. and D. P. Truex (2011) "Dropping Your Tools: Exploring When and How Theories Can Serve as Blinders in IS Research", Communications of the Association for Information Systems (28)19, pp. 283-294

Hutchinson, J., J. Whittle, and M. Rouncefield (2014) "Model-driven Engineering Practices in Industry: Social, Organizational and Managerial Factors that Lead to Success or Failure", Science of Computer Programming (89)Part B, pp. 144-161

Indulska, M., P. Green, J. Recker, and M. Rosemann (2009) "Business Process Modeling: Perceived Benefits", in Castano, S., U. Dayal, and A. H. F. Laender (eds.) Conceptual Modeling - ER 2009, Gramado, Brazil: Springer, pp. 458-471

Irwin, G. and D. Turk (2005) "An Ontological Analysis of Use Case Modeling Grammar", Journal of the Association for Information Systems (6)1, pp. 1-36

Jabbari Sabegh, M. A. and J. Recker (2017) "Combined Use of Conceptual Models in Practice: An Exploratory Study", Journal of Database Management (28)2, pp. 56-88

Kendall, K. E. and J. E. Kendall (2008) Systems Analysis and Design, 7th edition, Upper Saddle River, New Jersey: Prentice Hall

Khatri, V. and I. Vessey (2016) "Understanding the Role of IS and Application Domain Knowledge on Conceptual Schema Problem Solving: A Verbal Protocol Study", Journal of the Association for Information Systems (17)12, pp. 759-803

Khatri, V., I. Vessey, V. Ramesh, P. Clay, and P. Sung-Jin (2006) "Understanding Conceptual Schemas: Exploring the Role of Application and IS Domain Knowledge", Information Systems Research (17)1, pp. 81-99

Kim, J., J. Hahn, and H. Hahn (2000) "How Do We Understand a System with (So) Many Diagrams? Cognitive Integration Processes in Diagrammatic Reasoning", Information Systems Research (11)3, pp. 284-303

King, W. R. and J. He (2005) "Understanding the Role and Methods of Meta-Analysis in IS Research", Communications of the Association for Information Systems (16)32, pp. 665686

Klein, H. K. and M. D. Myers (1999) "A Set of Principles for Conducting and Evaluating Interpretive Field Studies in Information Systems", MIS Quarterly (23)1, pp. 67-94

Kung, C. H. and A. Sølvberg (1986) "Activity Modeling and Behavior Modeling of Information Systems", in Olle, T. W., H. G. Sol, and A. A. Verrijn-Stuart (eds.) Information Systems Design Methodologies: Improving the Practice, Amsterdam: North-Holland, pp. 145-171

Larkin, J. H. and H. A. Simon (1987) "Why a Diagram Is (Sometimes) Worth Ten Thousand Words", Cognitive Science (11)1, pp. 65-100

Lauesen, S. and O. Vinter (2001) "Preventing Requirement Defects: An Experiment in Process Improvement", Requirements Engineering (6)1, pp. 37-50

Leckie, G. J. (2005) "General Model of the Information Seeking of Professionals", in Fisher, K. E., S. Erdelez, and L. McKechnie (eds.) Theories of Information Behavior, Medford, New Jersey: Information Today, pp. 158-163 
Lindland, O. I., G. Sindre, and A. Solvberg (1994) "Understanding Quality in Conceptual Modeling", IEEE Software (11)2, pp. 42-49

Locke, E. A. and G. P. Latham (1990) A Theory of Goal Setting and Task Performance, Englewood Cliffs, New Jersey: Prentice-Hall

Lukyanenko, R., J. Parsons, and Y. F. Wiersma (2014a) "The Impact of Conceptual Modeling on Dataset Completeness: A Field Experiment", in Myers, M. D. and D. W. Straub (eds.) 35th International Conference on Information Systems, Auckland, New Zealand: Association for Information Systems,

Lukyanenko, R., J. Parsons, and Y. F. Wiersma (2014b) "The IQ of the Crowd: Understanding and Improving Information Quality in Structured User-Generated Content", Information Systems Research (25)4, pp. 669-689

Lukyanenko, R., J. Parsons, and Y. F. Wiersma (2016) "Emerging Problems of Data Quality in Citizen Science", Conservation Biology (30)3, pp. 447-449

Lukyanenko, R., J. Parsons, Y. F. Wiersma, G. Wachinger, B. Huber, and R. Meldt (2017) "Representing Crowd Knowledge: Guidelines for Conceptual Modeling of Usergenerated Content", Journal of the Association for Information Systems (18)4, pp. 297339

Maes, A. and G. Poels (2007) "Evaluating Quality of Conceptual Modelling Scripts Based on User Perceptions", Data \& Knowledge Engineering (63)3, pp. 769-792

March, J. G. (1991) "Exploration and Exploitation in Organizational Learning", Organization Science (2)1, pp. 71-87

Masri, K., D. C. Parker, and A. Gemino (2008) "Using Iconic Graphics in Entity-Relationship Diagrams: The Impact on Understanding", Journal of Database Management (19)3, pp. 22-41

Mayer, R. E. (1989) "Models for Understanding", Review of Educational Research (59)1, pp. 4364

Mayer, R. E. (2009) Multimedia Learning, 2nd edition, Cambridge, Massachusetts: Cambridge University Press

Mendling, J., M. Strembeck, and J. Recker (2012) "Factors of Process Model Comprehension - Findings from a Series of Experiments", Decision Support Systems (53)1, pp. 195206

Miller, G. A. (1956) "The Magical Number Seven, Plus or Minus Two: Some Limits on Our Capacity for Processing Information", Psychological Review (63)2, pp. 81-97

Milliken, F. J. (1987) "Three Types of Perceived Uncertainty About the Environment: State, Effect, and Response Uncertainty", Academy of Management Review (12)1, pp. 133-143

Mohagheghi, P., W. Gilani, A. Stefanescu, and M. A. Fernandez (2013) "An Empirical Study of the State of the Practice and Acceptance of Model-driven Engineering in Four Industrial Cases", Empirical Software Engineering (18)1, pp. 89-116

Moody, D. L. (2009) "The "Physics" of Notations: Toward a Scientific Basis for Constructing Visual Notations in Software Engineering", IEEE Transactions on Software Engineering (35)6, pp. 756-779

Newell, A. and H. A. Simon (1972) Human Problem Solving, Englewood Cliffs, New Jersey: Prentice-Hall

Nolte, A., E. Bernhard, J. Recker, F. Pittke, and J. Mendling (2016) "Repeated Use of Process Models: The Impact of Artifact, Technological, and Individual Factors", Decision Support Systems (88), pp. 98-111

Oliver, R. L. (1977) "Effect of Expectation and Disconfirmation on Postexposure Product Evaluations - an Alternative Interpretation", Journal of Applied Psychology (62)4, pp. 480-486

OMG (2011) "Business Process Model and Notation (BPMN) - Version 2.0", Object Management Group, http://www.omg.org/spec/BPMN/2.0 (current March 17, 2011) 
Opdahl, A. L. and B. Henderson-Sellers (2002) "Ontological Evaluation of the UML Using the Bunge-Wand-Weber Model", Software and Systems Modeling (1)1, pp. 43-67

Parsons, J. (2011) "An Experimental Study of the Effects of Representing Property Precedence on the Comprehension of Conceptual Schemas", Journal of the Association for Information Systems (12)6, pp. 401-422

Petre, M. (2013) "UML in Practice", in Cheng, B. H. C. and K. Pohl (eds.) 2013 International Conference on Software Engineering, San Francisco, California: IEEE, pp. 722-731

Pretz, J. E., A. J. Naples, and R. J. Sternberg (2003) "Recognizing, Defining, and Representing Problems", in Davidson, J. E. and R. J. Sternberg (eds.) The Psychology of Problem Solving, New York, New York: Cambridge University Press, pp. 3-30

Puolamäki, K. and A. Bertone (2009) "Introduction to the Special Issue on Visual Analytics and Knowledge Discovery", SIGKDD Explorations (11)2, pp. 3-4

Purao, S., M. Rossi, and A. Bush (2002) "Towards an Understanding of Problem and Design Spaces during Object-oriented Systems Development", Information and Organization (12)4, pp. 249-281

Recker, J. (2010) "Continued Use of Process Modeling Grammars: The Impact of Individual Difference Factors", European Journal of Information Systems (19)1, pp. 76-92

Recker, J. (2013) "Empirical Investigation of the Usefulness of Gateway Constructs in Process Models", European Journal of Information Systems (22)6, pp. 673-689

Recker, J. and A. Dreiling (2011) "The Effects of Content Presentation Format and User Characteristics on Novice Developers' Understanding of Process Models", Communications of the Association for Information Systems (28)6, pp. 65-84

Recker, J., M. Indulska, M. Rosemann, and P. Green (2010) "The Ontological Deficiencies of Process Modeling in Practice", European Journal of Information Systems (19)5, pp. 501525

Recker, J., M. Rosemann, P. Green, and M. Indulska (2011) "Do Ontological Deficiencies in Modeling Grammars Matter?", MIS Quarterly (35)1, pp. 57-79

Recker, J., M. Rosemann, M. Indulska, and P. Green (2009) "Business Process Modeling: A Comparative Analysis", Journal of the Association for Information Systems (10)4, pp. 333-363

rFigl, K. and J. Recker (2016) "Process Innovation as Creative Problem-Solving: An Experimental Study of Textual Descriptions and Diagrams", Information \& Management (53)6, pp. 767-786

Rioux, K. (2005) "Information Acquiring-and-Sharing", in Fisher, K. E., S. Erdelez, and L. McKechnie (eds.) Theories of Information Behavior, Medford, New Jersey: Information Today, pp. 169-173

Rosemann, M., P. Green, and M. Indulska (2004) "A Reference Methodology for Conducting Ontological Analyses", in Lu, H., W. Chu, P. Atzeni, S. Zhou, and T. W. Ling (eds.) Conceptual Modeling - ER 2004, Shanghai, China: Springer, pp. 110-121

Rosemann, M., J. Recker, P. Green, and M. Indulska (2009) "Using Ontology for the Representational Analysis of Process Modeling Techniques", International Journal of Business Process Integration and Management (4)4, pp. 251-265

Samuel, B. M., L. A. Watkins III, A. Ehle, and V. Khatri (2015) "Customizing the Representation Capabilities of Process Models: Understanding the Effects of Perceived Modeling Impediments ", IEEE Transactions on Software Engineering (41)1, pp. 19-39

Samuelson, P. A. and W. D. Nordhaus (2001) Microeconomics, 17th edition, Boston, Massachusetts: McGraw-Hill//rwin

Scott, J. (2000) "Rational Choice Theory", in Browning, G., A. Halcli, and F. Webster (eds.) Understanding Contemporary Society: Theories of the Present, Thousand Oaks, California: Sage, pp. 126-138 
Shanks, G., E. Tansley, J. Nuredini, D. Tobin, and R. Weber (2008) "Representing Part-Whole Relations in Conceptual Modeling: An Empirical Evaluation", MIS Quarterly (32)3, pp. 553-573

Siau, K. and L. Y. Lee (2004) "Are Use Case and Class Diagrams Complementary in Requirements Analysis: An Experimental Study on Use Case and Class Diagrams in UML", Requirements Engineering (9)4, pp. 229-237

Siau, K. and M. Rossi (2011) "Evaluation Techniques for Systems Analysis and Design Modelling Methods - A Review and Comparative Analysis", Information Systems Journal (21)3, pp. 249-268

Sweller, J. (1988) "Cognitive Load During Problem Solving: Effects on Learning", Cognitive Science (12)2, pp. 257-285

Truex, D. P. and R. Baskerville (1998) "Deep Structure or Emergence Theory: Contrasting Theoretical Foundations for Information Systems Development", Information Systems Journal (8)2, pp. 99-118

Tuovinen, J. E. and J. Sweller (1999) "A Comparison of Cognitive Load Associated With Discovery Learning and Worked Examples", Journal of Educational Psychology (91)2, pp. 334-341

Urquhart, C. and W. D. Fernandez (2013) "Using Grounded Theory Method in Information Systems: The Researcher as Blank Slate and Other Myths", Journal of Information Technology (28)3, pp. 224-236

Venkatesh, V. and F. D. Davis (2000) "A Theoretical Extension of the Technology Acceptance Model: Four Longitudinal Field Studies", Management Science (46)2, pp. 186-204

Venkatesh, V., M. G. Morris, G. B. Davis, and F. D. Davis (2003) "User Acceptance of Information Technology: Toward a Unified View", MIS Quarterly (27)3, pp. 425-478

Vessey, I. and D. F. Galletta (1991) "Cognitive Fit: An Empirical Study of Information Acquisition", Information Systems Research (2)1, pp. 63-84

Wand, Y. and R. Weber (1989) "An Ontological Evaluation of Systems Analysis and Design Methods", in Falkenberg, E. D. and P. Lindgreen (eds.) Information System Concepts: An In-depth Analysis. Proceedings of the IFIP TC 8/WG 8.1 Working Conference on Information System Concepts, Amsterdam, The Netherlands: North Holland, pp. 79-107

Wand, Y. and R. Weber (1990) "An Ontological Model of an Information System", IEEE Transactions on Software Engineering (16)11, pp. 1282-1292

Wand, Y. and R. Weber (1993) "On the Ontological Expressiveness of Information Systems Analysis and Design Grammars", Journal of Information Systems (3)4, pp. 217-237

Wand, Y. and R. Weber (1995) "On the Deep Structure of Information Systems", Information Systems Journal (5)3, pp. 203-223

Wand, Y. and R. Weber (2002) "Research Commentary: Information Systems and Conceptual Modeling - A Research Agenda", Information Systems Research (13)4, pp. 363-376

Ward, M. and J. Sweller (1990) "Structuring Effective Worked Examples", Cognition and Instruction (7)1, pp. 1-39

Weber, R. (1997) Ontological Foundations of Information Systems, Melbourne, Australia: Coopers \& Lybrand and the Accounting Association of Australia and New Zealand

Weber, R. (2012) "Evaluating and Developing Theories in the Information Systems Discipline", Journal of the Association for Information Systems (13)1, pp. 1-30

Weber, R. and Y. Zhang (1996) "An Analytical Evaluation of NIAM's Grammar for Conceptual Schema Diagrams", Information Systems Journal (6)2, pp. 147-170

Whetten, D. A. (1989) "What Constitutes a Theoretical Contribution?", Academy of Management Review (14)4, pp. 490-495

Whiteley, D. (2013) An Introduction to Information Systems, London, England: Palgrave Macmillan 
Whittle, J., J. Hutchinson, and M. Rouncefield (2014) "The State of Practice in Model-Driven Engineering", IEEE Software (31)3, pp. 79-85

Wilson, T. D. (1999) "Models in Information Behaviour Research", Journal of Documentation (55)3, pp. 249-270

Wood, C., B. Sullivan, M. Iliff, D. Fink, and S. Kelling (2011) "eBird: Engaging Birders in Science and Conservation", PLoS Biology (9)12, pp. e1001220

Xue, L., G. Ray, and B. Gu (2011) "Environmental Uncertainty and IT Infrastructure Governance: A Curvilinear Relationship", Information Systems Research (22)2, pp. 389399

Yourdon, E. (1989) Modern Structured Analysis, Upper Saddle River, New Jersey: Prentice-Hall

Zhang, H., R. Kishore, R. Sharman, and R. Ramesh (2007) "Agile Integration Modeling Language (AIML): A Conceptual Modeling Grammar for Agile Integrative Business Information Systems", Decision Support Systems (44)1, pp. 266-284

Zigurs, I. and B. K. Buckland (1998) "A Theory of Task/Technology Fit and Group Support Systems Effectiveness", MIS Quarterly (22)3, pp. 313-334

zur Muehlen, M. and M. Indulska (2010) "Modeling Languages for Business Processes and Business Rules: A Representational Analysis", Information Systems (35)4, pp. 379-390

zur Muehlen, M. and J. Recker (2008) "How Much Language is Enough? Theoretical and Practical Use of the Business Process Modeling Notation", in Léonard, M. and Z. Bellahsène (eds.) Advanced Information Systems Engineering - CAiSE 2008, Montpellier, France: Springer, pp. 465-479 


\section{APPENDIX A: BACKGROUND TO REPRESENTATION THEORY AND DEFINITIONS OF KEY CONSTRUCTS}

Representation theory (Wand and Weber, 1990; 1993; 1995) addresses the question how well conceptual modeling grammars can generate faithful (i.e., clear, complete, and accurate, see Weber, 1997, p. 83) representations of relevant real-world phenomena. To identify relevant types of real-world phenomena, the theory adopts and modifies an ontological theory of the real world proposed by Bunge $(1977 ; 1979)$. Representation theory suggests a mapping between the set of existing constructs in a conceptual modeling grammar that is available to the user to model aspects of the real world, and the set of constructs in a benchmark ontology (such as Bunge's) that are required and sufficient to describe real-world phenomena. ${ }^{4}$ Based on this mapping, Wand and Weber (1993) suggest two basic criteria: A good modeling grammar or indeed a good conceptual model should be ontologically complete (viz., exhibit no construct deficit) and ontologically clear (viz., exhibit no construct overload, redundancy, or excess) to describe accurately and unambiguously all required real-world phenomena in the business domain an IS is intended to support.

Relevant construct definitions of Wand and Weber's theory are provided in Table A1. The theory and the literature it supports is reviewed by Burton-Jones et al. (2017) so we do not discuss it in detail here. However, three observations about this literature are relevant to our paper:

1. The theory has been subjected to various tests and applications (Burton-Jones et al., 2017). However, this research has largely been on single grammars or single models, examining questions like whether ontological deficiencies in a grammar lower perceptions of its usefulness (Recker et al., 2011), whether ontological deficiencies in a grammar inhibit users'

4 Representation theory is not tied to a specific ontological model. While Bunge's ontological theory is often used, other benchmark ontologies could and should be used (Wand and Weber, 1993, p. 221). 
ability to model a particular real-world phenomenon faithfully (e.g., Bodart et al., 2001; Shanks et al., 2008; Parsons, 2011), and whether users' ability to understand a real-world domain is inhibited by deficiencies in the conceptual model (e.g., Gemino and Wand, 2005; Bowen et al., 2006; Evermann and Wand, 2006; Bera et al., 2011).

1. All theory-based evaluations of conceptual modeling grammars (e.g., UML, OML, OPM, ERD, DFD, BPMN, Petri nets, MibML, WSDL, BPEL, and others) to date have shown that no available grammar is ontologically complete (e.g., Wand and Weber, 1993; Weber and Zhang, 1996; Opdahl and Henderson-Sellers, 2002; Irwin and Turk, 2005; Green et al., 2007; Recker et al., 2009). Therefore, even users who wanted to create models that fully represent all aspects of the real-world phenomena they want to represent cannot. Therefore, no single conceptual model offers a full representation of a real-world domain. Green (1996) and Weber (1997, pp. 100-102) therefore predicted that users would employ modeling grammars in combination to address deficits in any one grammar. They made two predictions. First, model designers select grammar combinations with maximal ontological completeness, that is, a combination that minimizes total construct deficit and covers as many aspects of the focal real-world phenomenon as possible. Second, model designers select grammar combinations with minimal ontological overlap, that is, combinations that minimize the grammars' overlap of representations of real-world phenomena that can be modelled.

Work was then conducted to develop propositions and gather data about which grammar combinations designers might select (Green et al., 2007; zur Muehlen and Indulska, 2010; Green et al., 2011). But this work has not been extended to examine model readers' interpretations of combinations of models (rather than the grammars with which they have been constructed). 
2. The existing empirical work has demonstrated that ontological deficiencies can predict weaknesses in the use of the conceptual models or grammars. Yet, these effects are not uniform or consistent. On one hand, implications of ontological incompleteness appear clear: The lack of potentially relevant information about a real-world domain diminishes the level of understanding users can generate (e.g., Bajaj, 2004; Parsons, 2011), which often leads them to seek workarounds and customizations (Recker et al., 2010; Green et al., 2011; Samuel et al., 2015). They devise new grammatical constructs, access additional grammars or "aids," or refer to additional documentation to provide the meaning missing from the model. On the other hand, deficiencies of ontological clarity, in particular redundancy, do not always have clear effects (Fickinger and Recker, 2013). Construct redundancy can have positive consequences for users (Green and Rosemann, 2001), no apparent consequences (Recker et al., 2010), or only partially negative consequences (Recker et al., 2011). Therefore, redundancy of representations between models may be either beneficial or a detriment.

These observations indicate at least one non-trivial dialectical logic involved in how individuals might interpret multiple models in combination: on the one hand, it seems logical for users to seek multiple models if these models would provide a more complete representation of a realworld domain. On the other hand, multiple models are often at least partially redundant, as information from one model may also be contained in a second model, so the representations may partially overlap. It remains unclear whether this situation yields an advantage or an issue: Wand and Weber's theory predicts a lack of clarity from redundancy, but the empirical evidence from single grammars (Recker et al., 2010; Recker et al., 2011) and even multiple grammars (Green and Rosemann, 2001; Gemino and Parker, 2009) suggests that users may sometimes experience benefits from redundancies. Our theory development provides an attempt to unpack this dialectic. 
Table A1. Key Construct Definitions

\begin{tabular}{|c|c|c|}
\hline Construct & Definition & $\begin{array}{c}\text { Relevant } \\
\text { Reference }\end{array}$ \\
\hline Representation & $\begin{array}{l}\text { A model of someone's or some group's perception of the meaning } \\
\text { of a real-world phenomenon. }\end{array}$ & $\begin{array}{l}\text { (Wand and } \\
\text { Weber, 1995, p. } \\
\text { 207) }\end{array}$ \\
\hline $\begin{array}{l}\text { Real-world } \\
\text { Phenomenon }\end{array}$ & $\begin{array}{l}\text { The aggregation of constituent things and their properties that } \\
\text { exist in the real world, as perceived by someone or some group. }\end{array}$ & $\begin{array}{l}\text { (Weber, 1997, p. } \\
34 \& 72 \text { ) }\end{array}$ \\
\hline Conceptual Model & $\begin{array}{l}\text { The script (i.e., a meaningful, orderly collection of symbols) that } \\
\text { embodies the description of the real-world phenomenon as } \\
\text { perceived by someone or some group. }\end{array}$ & $\begin{array}{l}\text { (Weber, 1997, p. } \\
75)\end{array}$ \\
\hline $\begin{array}{l}\text { Combined } \\
\text { Ontological } \\
\text { Completeness }\end{array}$ & $\begin{array}{l}\text { The extent to which a conceptual model combination of two or } \\
\text { more scripts provides a full representation of someone's or some } \\
\text { group's perception of the meaning of some real-world } \\
\text { phenomenon. }\end{array}$ & $\begin{array}{l}\text { Newly developed } \\
\text { construct }\end{array}$ \\
\hline Ontological Overlap & $\begin{array}{l}\text { The extent to which two or more scripts in a conceptual model } \\
\text { combination share model constructs that provide the same } \\
\text { representation of some real-world phenomenon. }\end{array}$ & $\begin{array}{l}\text { Newly developed } \\
\text { construct }\end{array}$ \\
\hline $\begin{array}{l}\text { Maximal Ontological } \\
\text { Completeness }\end{array}$ & $\begin{array}{l}\text { The fullest level of representation of someone's or some group's } \\
\text { perception of the meaning of some real-world phenomenon } \\
\text { attained by one out of several combinations of conceptual models. }\end{array}$ & $\begin{array}{l}\text { Newly developed } \\
\text { construct }\end{array}$ \\
\hline $\begin{array}{l}\text { Minimal Ontological } \\
\text { Overlap }\end{array}$ & $\begin{array}{l}\text { The lowest level of shared representations of someone's or some } \\
\text { group's perception of the meaning of some real-world } \\
\text { phenomenon in one out of several combinations of conceptual } \\
\text { models. }\end{array}$ & $\begin{array}{l}\text { Newly developed } \\
\text { construct }\end{array}$ \\
\hline $\begin{array}{l}\text { Interpretation of } \\
\text { Conceptual Models }\end{array}$ & $\begin{array}{l}\text { The extent to which reading one or more conceptual models } \\
\text { provides an individual user with a complete, clear, and accurate } \\
\text { understanding of the meaning of the described real-world } \\
\text { phenomenon in a goal-directed activity. }\end{array}$ & $\begin{array}{l}\text { Newly developed } \\
\text { construct }\end{array}$ \\
\hline $\begin{array}{l}\text { Selection of Model } \\
\text { Combination }\end{array}$ & $\begin{array}{l}\text { The decision to choose to employ one set of two or more } \\
\text { conceptual models for a given task from a larger set of available } \\
\text { conceptual models. }\end{array}$ & $\begin{array}{l}\text { Newly developed } \\
\text { construct }\end{array}$ \\
\hline $\begin{array}{l}\text { Domain } \\
\text { Understanding }\end{array}$ & $\begin{array}{l}\text { The new knowledge that readers generate about the elements in a } \\
\text { real-world domain and the actual and possible relationships } \\
\text { between these elements through the organization and integration } \\
\text { of information content in the conceptual models that are presented } \\
\text { to them with their own previous experience and existing mental } \\
\text { models. }\end{array}$ & $\begin{array}{l}\text { Adapted from } \\
\text { (Mayer, 2009) }\end{array}$ \\
\hline $\begin{array}{l}\text { Perceived } \\
\text { Usefulness of Model } \\
\text { Combination }\end{array}$ & $\begin{array}{l}\text { The degree to which a reader believes that a particular conceptual } \\
\text { model combination was effective in achieving the intended task } \\
\text { objectives. }\end{array}$ & $\begin{array}{l}\text { Adapted from } \\
\text { (Maes and Poels, } \\
\text { 2007, p. 709) }\end{array}$ \\
\hline
\end{tabular}




\section{APPENDIX B: ILLUSTRATING PROCEDURES FOR ENACTING THE THEORY}

Here we describe procedures for applying our theory to the analysis of multiple models. To keep this illustration simple, we use materials from an established textbook for systems analysis and design: the High-Peak Bicycles case described by Whiteley (2013, pp. 228-263). We chose this case simply because the textbook features a wide selection of models for this scenario.

The case describes the composition of an information system to maintain records of bicycle rentals, with requirements that the system allows for maintaining a bike register, renting out and returning rentals, allocating bikes, processing transactions, and other functionality. We focus on four types of models used in the case: use case, entity-relationship, data flow, and sequence diagram (Figure B1). ${ }^{5}$

The procedure for analyzing the four models used in the High-Peak Bicycles case involves three steps: (1) performing an interpretation mapping, (2) establishing levels of maximal ontological completeness and minimal ontological overlap, and (3) deriving hypotheses from the analysis. We describe each, in turn.

$5 \quad$ We selected these types of models because the relevant grammars have been analyzed using representation theory (Wand and Weber, 1989; Opdahl and Henderson-Sellers, 2002; Irwin and Turk, 2005; Green et al., 2011). We do not provide a detailed description of the grammars because that information is available in many textbooks (e.g., Yourdon, 1989; Fowler, 2004; Whiteley, 2013). 

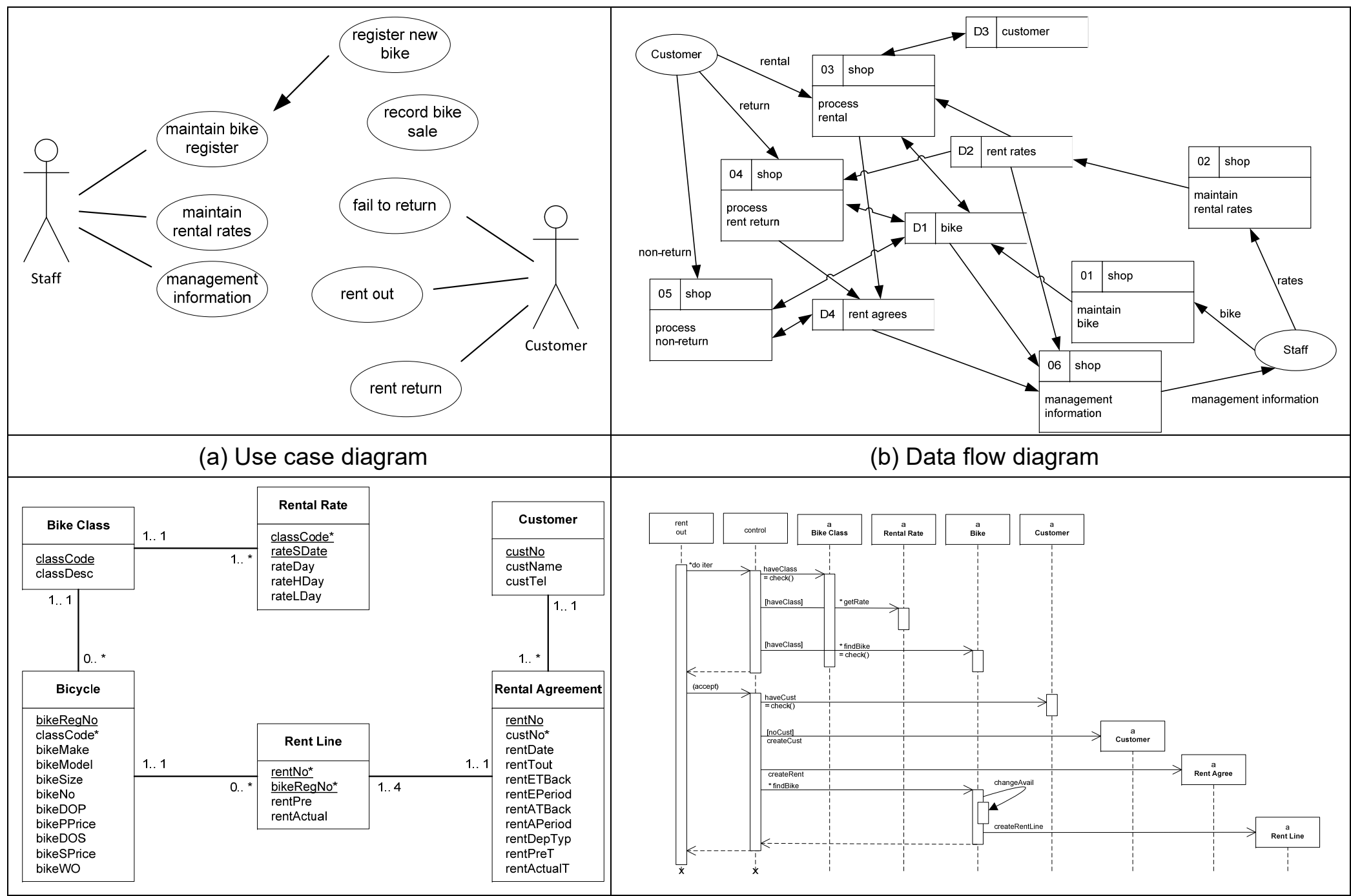

(b) Data flow diagram

(c) Entity-relationship diagram

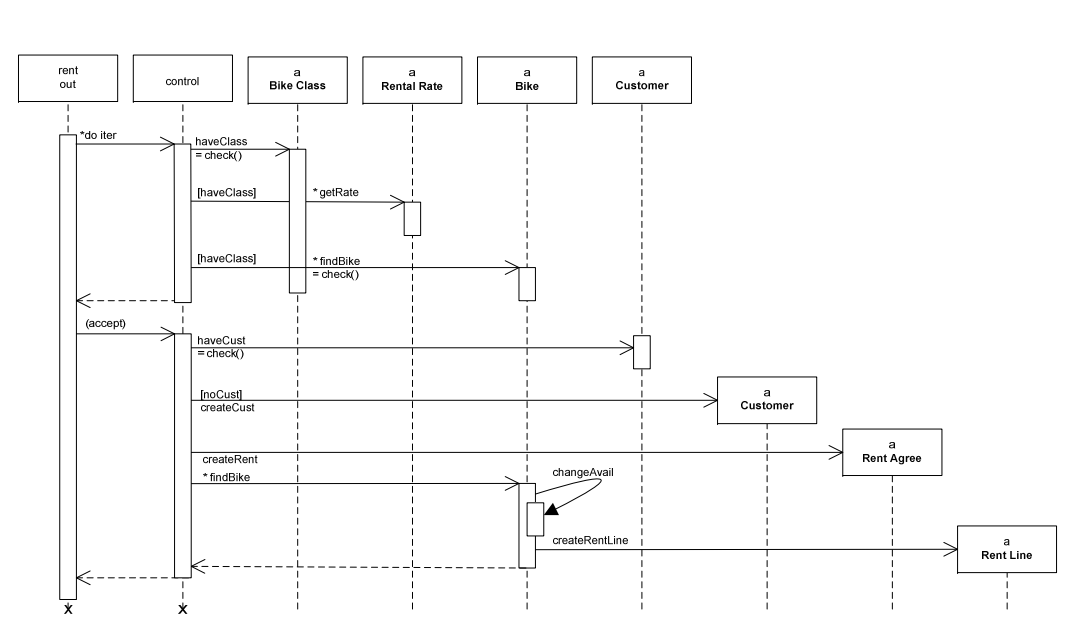

(d) Sequence diagram

Figure B1: Conceptual models for the High-Peak Bicycles case (Whiteley, 2013, pp. 228-263) 
The first step, interpretation mapping (Wand and Weber, 1993, p. 221), involves matching grammar constructs featuring in each of the models to an ontological benchmark such as Bunge's $(1977 ; 1979)$ ontological theory. The constructs described in Bunge's ontology as used in representation theory are summarized by Recker et al. (2009). A detailed description of these constructs is provided by Weber (1997). Guidelines for carrying out interpretation mappings are also available (Rosemann et al., 2004; Rosemann et al., 2009). For the four models in the High-Peak Bicycles case, we conducted the interpretation mapping in three steps:

1. We identified the published ontological analyses for the grammars used to create the four diagrams. Irwin and Turk (2005) evaluated the use case modeling grammar; Wand and Weber (1989) evaluated the data flow diagramming grammar; Green et al. (2011) evaluated the entity-relationship modeling grammar; and Opdahl and Henderson-Sellers (2002) evaluated sequence diagrams as part of the UML grammar.

2. For each grammar, we identified all grammar constructs included in the models shown in Figure B1. For instance, the use case diagram in the case includes the constructs "Actor" and "Use Case" but not the constructs "System" or "Extend" (Irwin and Turk, 2005, p. 5).

3. For each construct, we reviewed the grammar mappings and corresponding mapping rationale in the original analyses to confirm that they applied to the models in Figure B1. This task was important especially for grammar constructs that are overloaded per grammar specification (that is, it mapped to at least two ontological constructs, see Wand and Weber, 1993). In such instances, it was important to evaluate which meaning was ascribed to the construct in the model in order to identify the corresponding ontological construct present in the model. This step was important because interpretation mappings in general are not just a 1:1 correspondence of ontological to grammatical constructs. Therefore, in any model, overloaded grammar constructs could have more than one ontological interpretation. Still, 
for validity and replicability purposes, we remained with the interpretations from the literature (point 1 above) wherever possible.

Table B2 details the rationales behind each mapping, and Table B3 summarizes the mapping results. Across the four diagrams, a total of ten distinct ontological constructs are represented.

\section{Table B2. Ontological Evaluations of Conceptual Model Constructs in the Case}

\begin{tabular}{|c|c|c|c|c|}
\hline $\begin{array}{l}\text { Conceptual } \\
\text { Model } \\
\text { Type }\end{array}$ & $\begin{array}{l}\text { Grammar } \\
\text { Construct }\end{array}$ & $\begin{array}{l}\text { Example } \\
\text { Construct } \\
\text { Symbol }\end{array}$ & $\begin{array}{l}\text { Ontological } \\
\text { Construct }\end{array}$ & Rationale \\
\hline \multirow[t]{4}{*}{$\begin{array}{l}\text { Use case } \\
\text { diagram }\end{array}$} & Actor & & Class & $\begin{array}{l}\text { Staff and Customer are roles, that } \\
\text { describe specific types of things } \\
\text { (e.g., humans). See Irwin and Turk } \\
\text { (2005, p. 13). }\end{array}$ \\
\hline & Use case & & Transformation & $\begin{array}{l}\text { Use cases describe sets of actions } \\
\text { as mappings that will change the } \\
\text { state of the system. }\end{array}$ \\
\hline & Association & & $\begin{array}{l}\text { Binding mutual } \\
\text { property }\end{array}$ & $\begin{array}{l}\text { Associations draw links between } \\
\text { actors and use cases, such as which } \\
\text { role is authoritative for carrying out } \\
\text { an action. }\end{array}$ \\
\hline & Generalization & & Excess & $\begin{array}{l}\text { Generalization between use cases } \\
\text { does not carry an ontological } \\
\text { meaning because it violates the "kind } \\
\text { of" relationship that can exist } \\
\text { between things (but not between } \\
\text { processes and changes of states. } \\
\text { See Irwin and Turk (2005, p. 13). }\end{array}$ \\
\hline \multirow[t]{5}{*}{$\begin{array}{l}\text { Data flow } \\
\text { diagram }\end{array}$} & External entity & & Class & $\begin{array}{l}\text { External entities represent types of a } \\
\text { thing that share similar properties. }\end{array}$ \\
\hline & Data store & \begin{tabular}{l|l|} 
D3 & customer \\
\end{tabular} & State & $\begin{array}{l}\text { Data stores represent information } \\
\text { about the state of a thing (e.g., the } \\
\text { current values of relevant variables } \\
\text { about a customer). See Wand and } \\
\text { Weber (1989, p. } 92) \text {. }\end{array}$ \\
\hline & Data flow & & Event & $\begin{array}{l}\text { Data flows can represent external } \\
\text { events (e.g., rental) or internal } \\
\text { events (e.g., non-return). }\end{array}$ \\
\hline & \multirow[t]{2}{*}{ Process } & \begin{tabular}{l|l}
02 & shop
\end{tabular} & \multirow[t]{2}{*}{ Transformation } & \multirow{2}{*}{$\begin{array}{l}\text { Processes describe mappings that } \\
\text { define how things change from one } \\
\text { state into another. }\end{array}$} \\
\hline & & $\begin{array}{l}\text { maintain } \\
\text { rental rates }\end{array}$ & & \\
\hline
\end{tabular}




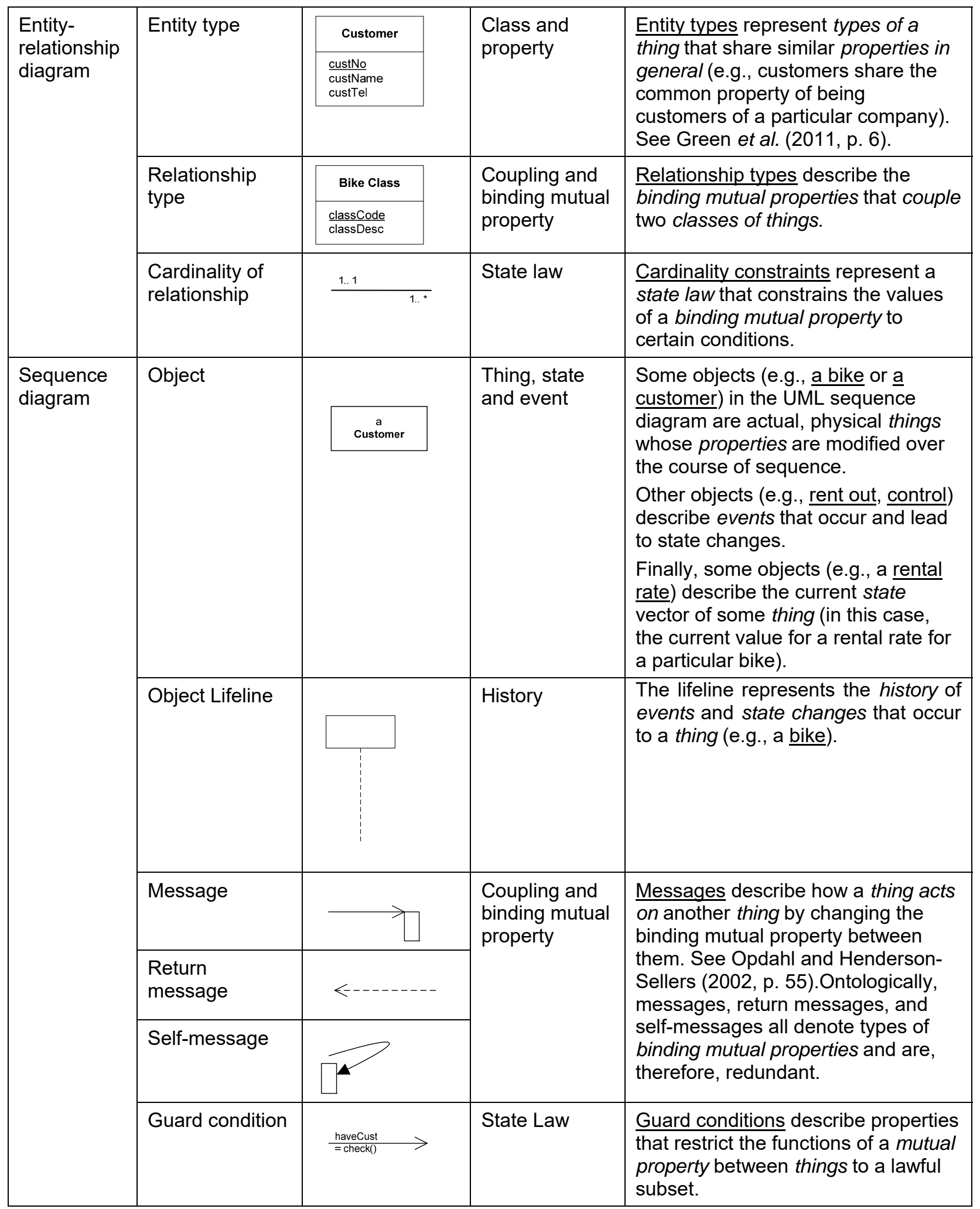

Legend: Underlined terms are constructs and labels used in the diagrams in Figure 6. Italic terms are constructs in representation theory (Weber, 1997) as defined by Recker et al. (2009, p. 361). 


\section{Table B3. Summary of interpretation mapping of the four conceptual models}

\begin{tabular}{|l|l|l|l|l|}
\hline Ontological construct & $\begin{array}{l}\text { Use case } \\
\text { diagram }\end{array}$ & $\begin{array}{l}\text { Data flow } \\
\text { diagram }\end{array}$ & $\begin{array}{l}\text { Entity-relationship } \\
\text { diagram }\end{array}$ & $\begin{array}{l}\text { Sequence } \\
\text { diagram }\end{array}$ \\
\hline Thing & & & $\checkmark$ & $\checkmark$ \\
\hline Property in general & & & $\checkmark$ & $\checkmark$ \\
\hline Binding mutual property & $\checkmark$ & $\checkmark$ & $\checkmark$ & \\
\hline Class & $\checkmark$ & $\checkmark$ & $\checkmark$ & $\checkmark$ \\
\hline State & & & & $\checkmark$ \\
\hline State Law & & $\checkmark$ & & $\checkmark$ \\
\hline Event & & & $\checkmark$ & $\checkmark$ \\
\hline History & & & & $\checkmark$ \\
\hline Coupling & & $\checkmark$ & 5 out of 10 & 7 out of 10 \\
\hline Transformation & $\checkmark$ & 4 out of 10 &
\end{tabular}

The next step in in applying our theory involves determining the levels of $M O C$ and $M O O$ of the possible combinations of conceptual models. This is done by computing the sum of covered ontological constructs represented in any combination (MOC) and the sum of shared ontological constructs (MOO) in any combination. Table B4 and Table B5 summarize these results. ${ }^{6}$

\begin{tabular}{|l|l|l|l|l|}
\hline Table B4. MOC and MOO of Pairwise Combinations of Conceptual \\
Models in the High-Peak Bicycles Case \\
\hline Diagram type & $\begin{array}{l}\text { Use case } \\
\text { diagram }\end{array}$ & $\begin{array}{c}\text { Data flow } \\
\text { diagram }\end{array}$ & $\begin{array}{c}\text { Entity-relationship } \\
\text { diagram }\end{array}$ & $\begin{array}{c}\text { Sequence } \\
\text { diagram }\end{array}$ \\
\hline $\begin{array}{l}\text { Use case } \\
\text { diagram }\end{array}$ & 0 & 2 & 2 & 1 \\
\hline $\begin{array}{l}\text { Data flow } \\
\text { diagram }\end{array}$ & 5 & 0 & 1 & 2 \\
\hline $\begin{array}{l}\text { Entity- } \\
\text { relationship } \\
\text { diagram }\end{array}$ & 6 & 8 & 0 & 3 \\
\hline $\begin{array}{l}\text { Sequence } \\
\text { diagram }\end{array}$ & 9 & 9 & 9 & 0 \\
\hline
\end{tabular}

In Table B4, MOC of the combinations is given in the darker grey cells below the diagonal; MOO is given in the lighter grey cells above the diagonal. 


\begin{tabular}{|c|c|c|c|c|}
\hline $\begin{array}{l}\text { Use case } \\
\text { diagram } \\
\text { Data flow } \\
\text { diagram } \\
\text { Entity- } \\
\text { relationship } \\
\text { diagram }\end{array}$ & $\begin{array}{l}\text { Use case diagram } \\
\text { Data flow } \\
\text { diagram } \\
\text { Sequence } \\
\text { diagram }\end{array}$ & $\begin{array}{l}\text { Use case } \\
\text { diagram } \\
\text { Entity- } \\
\text { relationship } \\
\text { diagram } \\
\text { Sequence } \\
\text { diagram }\end{array}$ & $\begin{array}{l}\text { Data flow diagram } \\
\text { Entity-relationship } \\
\text { diagram } \\
\text { Sequence } \\
\text { diagram }\end{array}$ & $\begin{array}{l}\text { Use case diagram } \\
\text { Data flow diagram } \\
\text { Entity-relationship } \\
\text { diagram } \\
\text { Sequence } \\
\text { diagram }\end{array}$ \\
\hline MOC: 8 & MOC: 9 & MOC: 10 & MOC: 10 & MOC: 10 \\
\hline MOO: 3 & MOO: 5 & MOO: 4 & MOO: 6 & MOO: 7 \\
\hline
\end{tabular}

Having determined the levels of $M O C$ and $M O O$ of the possible combinations of conceptual models, we can now evaluate which combinations are preferable. Because conceptual model interpretation is a goal-directed activity occurring as part of some task, we will assume in what follows that the task is systems analysis and design (Kendall and Kendall, 2008).

We examine pairwise combinations first. The best model combination in terms of maximal ontological completeness is the sequence diagram with a choice of the use case, the data flow, or the entity-relationship diagram (Table B4). All three pairs cover nine of ten ontological constructs (Table B3). The worst combination is the use case diagram and the data flow diagram, which covers only five ontological constructs. In terms of minimal ontological overlap, either the combination of the entity-relationship diagram with the data flow diagram or the combination of the sequence diagram with the use case diagram achieves an overlap of one construct (class and binding mutual property, respectively; see Table B3). The worst combination is the entity-relationship diagram with the sequence diagram, which shares representations for three ontological constructs (binding mutual property, state law, and coupling). In terms of both maximal ontological completeness and minimal ontological overlap, Table B4 suggests that the best pairwise combination is the use case diagram and the sequence diagram (MOC: 9 . MOO: 1 ) because both remaining maximally ontologically complete pairs have an overlap of two constructs. 
An examination of all other potential 3-way and 4-way model combinations (Table B5) suggests that the optimal combination is the triple-use case, entity-relationship, and sequence diagrambecause it achieves MOC (all ten constructs) with MOO (four constructs). From the viewpoint of maximal ontological completeness, the worst combination is the triple-the use case, the data flow, and the entity-relationship diagram (MOC: 8). From the viewpoint of minimal ontological overlap, the worst combination is the triple data flow, the entity-relationship, and the sequence diagram (MOO: 6). Note that the combination of all four models (MOC: $10, \mathrm{MOO}: 7$ ) is worse for interpretation than the noted optimal triple because it achieves the same level of ontological completeness while having higher levels of ontological overlap.

The final step in applying our theory is to derive propositions about users' selection, understanding, and perceived usefulness of conceptual model combinations (for the task of systems analysis and design) from the analysis summarized in Table B4 and Table B5.

Regarding proposition 1, our theory suggests that users will select from the set of diagrams in the following order: first, the sequence diagram and the entity-relationship diagram (because this combination has the highest increase in ontological completeness); and second, the addition of the use case diagram (because in this combination ontological overlap increases to a lesser extent than it does with the data flow diagram, while both additions increase ontological completeness in the same way). Should the data flow diagram be selected in addition, the theory suggests that users will discard this diagram from the combination in order to decrease the level of ontological overlap.

Regarding proposition 2, our analysis suggests, first, that users will generate the highest level of domain understanding when interpreting the triple-use case diagram, the entity-relationship diagram, and the sequence diagram and, second, that interpreting this triple will allow users to generate more domain understanding than will interpreting all four diagrams together because the triple exhibits less ontological overlap while exhibiting the same level of completeness. 
Regarding proposition 3, our analysis suggests, first, that users will evaluate the triple-the use case diagram, the entity-relationship diagram, and the sequence diagram—as the most useful combination. Our analysis also suggests that the perceived usefulness of all four diagrams will be lower than the perceived usefulness of said triple. Finally, users will perceive the pair-use case diagram and sequence diagram—as more useful than all four diagrams together. This situation occurs because, even though the combined ontological completeness is lower in the pair, the ontological overlap is much lower than it is between all four models. Our theory suggests that practitioners will evaluate this pair as "useful enough" for the tasks at hand.

To summarize, we provided this illustration of procedure to demonstrate how to apply our theory to generate empirically falsifiable predictions, i.e., testable hypotheses. It was not our intent to demonstrate that the hypotheses are unequivocally correct but rather to show that the theory we formulated allows both for analysis (what are the ontological properties of various combinations of conceptual models?) and explanation (which combinations do users evaluate as faithful?) (Gregor, 2006). 


\section{APPENDIX C: ESTABLISHING BOUNDARY CONDITIONS THROUGH EMPIRICAL RESEARCH}

Recall that our theory describes a model of properties vested in conceptual models as artefacts. This focus entails several assumptions that limit the scope of contexts in which our theory holds. We describe several potential boundary conditions in the Discussion section of the paper. Still, we wish to encourage researchers to seek out even more boundaries because through such work greater faith can be placed in a theory from the knowledge of the conditions where and why predictions of the theory succeed or fail (Gray and Cooper, 2010).

One way to tease out a theory's boundaries further would be through the use of meta-analysis to quantitatively assess whether a theory's assumptions and predications hold under a wide range of circumstances (King and He, 2005). This approach, however, requires a large sample of empirical studies. Another way is to investigate how potential moderators affect the associations stipulated in a theory (Edwards and Berry, 2010, p. 676). Given that our theory has not yet been tested empirically, we find this approach more useful because contemplating potential moderator variables could feature in the design of empirical studies to evaluate our propositions. In what follows, we describe what we believe are three relevant variables that should be incorporated into research designs as potential moderators, and we present arguments how they might influence what we regard as the principal proposition in our theory: the development of domain understanding from interpreting multiple conceptual models. We leave the exploration of variations on the other propositions to another time. Of course, our speculations remain tentative at this stage: the role of the variables may also be as control, interaction or mediation terms. Still, they remain important to the design of a study. 


\section{Environmental uncertainty}

One assumption is central to our theory: the primary aim for the interpretation of conceptual models in isolation or in combination is to obtain a complete, clear, and accurate representation of the relevant real-world phenomenon (Wand and Weber, 1990; 1993). This assumption might be challenged in some contexts, as "complete, clear and accurate" might not always be a central aim for many tasks. ${ }^{7}$ For example, practices that involve system analysis and design have changed. One apparent shift is the move away from legacy systems and packaged software toward agile approaches to systems development (Fowler and Highsmith, 2001). Agile approaches to systems development embrace readiness "to rapidly or inherently create change, proactively or reactively embrace change, and learn from change while contributing to perceived customer value (economy, quality, and simplicity), through its collective components and relationships with its environment" (Conboy, 2009, p. 340). This context presents challenges to traditional uses of conceptual modeling (Erickson et al., 2005; Zhang et al., 2007) because the environment in which conceptual models are used is more fluid, emergent, complex, and dynamic: models of systems are rapidly being translated into running prototypes; new system structure and features emerge through constant and frequent feedback, and requirements changes are embraced. In turn, analysts and designers cannot fully anticipate how a system will evolve, what new functionality might be added, or what purposes in the real-world domain the system might need to satisfy. Overall, the context for the use of conceptual models in such settings is characterized by environmental uncertainty. ${ }^{8}$

$7 \quad$ We are grateful to the review team for alerting us to this challenge. As one reviewer put it: "For example, incomplete and inaccurate throw-away conceptual models have their uses too."

8 We adopted the term environmental uncertainty from studies on management and governance decisions, which employ the term in a similar manner (Milliken, 1987; Xue et al., 2011). Our use of this term, like their use, builds on Dess and Beard's (1984) theory of task environments. 
In task settings that are characterized by environmental uncertainty, the clarity of representation provided by conceptual models might be more important than their completeness. If the context in which individuals interpret representations as they perform tasks is unclear, users encounter more stimuli to process (e.g., task, representation, changing requirements, different stakeholders, evolving features, changing deep structure). In such situations, any way to reduce cognitive load will help them select, process, and integrate relevant information in their mental representations and perform their tasks (Mayer, 2009). Cognitive load in the interpretation of conceptual models stems from the number of representational elements provided (which can be reduced by reducing the combined ontological completeness of conceptual models) and the representational elements' lack of clarity (which can be increased by lowering the ontological overlap of conceptual models). Therefore, in task contexts characterized by high environmental uncertainty, the positive impact of a model combination's combined ontological completeness on users' ability to generate domain understanding might be diminished and the negative impact of a model combination's ontological overlap on users' ability to generate domain understanding might be strengthened.

\section{Task nature}

Tasks that involve the processing of information conveyed in models are also changing. For example, an article in this journal from April 2017 discusses challenges to common conceptual modeling assumptions that flow from organizations' increasing reliance on externally produced information, such as online user-generated content (Lukyanenko et al., 2017).

This and other apparent shifts in information processing tasks can be described as a move in emphasis from exploitative to explorative tasks (March, 1991). Explorative tasks are characterized by a search for novel and innovative ways of doing things burton-and are associated with experimentation, play, innovation, and/or discovery (March, 1991). In such tasks, available information may be used for purposes other than those for which the 
information was originally collected or the representation of the information was developed (Lukyanenko et al., 2014b). For example, citizen science projects involve mining user-generated content about some real-world domain (e.g., observations of native birds in some region) for unanticipated, novel, and interesting insights (Wood et al., 2011). Likewise, in the organizational redesign of operational procedures, analysts read conceptual models with the aim of finding creative solutions about how operational processes might be improved (rFigl and Recker, 2016), without knowing ex ante what the solution might look like. The lack of predefined outcomes and unanticipated expectations about the informational needs has important implications for conceptual modeling: quality of information is no longer defined only by precision, accuracy, or other traditional metrics (Lukyanenko et al., 2016) but must include an evaluation of the ability "to spot something interesting, unexpected, or novel" (p. 448).

It is likely that in contexts in which the nature of the task setting moves from exploitation to exploration, the strength of the associations between combined ontological completeness and ontological overlap on individual's ability to generate domain understanding varies as well. For example, in model interpretation settings characterized by explorative rather than exploitative tasks, the completeness of representation that conceptual models provide might be more important than their clarity because informational needs are difficult to anticipate and may even be fluid. What constitutes a relevant aspect of some real-world phenomenon cannot always be predefined. For example, Lukyanenko et al. (2014a, p. 6) observe how even small citizen science projects concerned with conservation in local, confined geographic areas may find it impossible to develop a classification model suitable to describe everything that might be observed because distributions of plants and animals are simply not static.

In settings where a task is geared toward exploration, excluding some such aspect in a representation could potentially lead to inaccurate uses (e.g., misidentifications), failure to spot relevant insights, and thus misinformation. Indeed, Lukyanenko et al. (2014a, p. 11) report on 
several observed patterns of mis-matching and mis-classification stemming from the way the information about the relevant phenomena (here: animal species observed by citizens) was described in the conceptual model underlying the database structure.

Potential deficiencies in a representation's clarity, by contrast, may not differ much between task settings of an explorative or exploitative nature, because they can likely be mitigated. For example, many explorative tasks such as knowledge discovery do not act on models or data schema directly but are supported by tools that build on visual analytics (Puolamäki and Bertone, 2009) to convey and communicate information about a real-world domain in a variety of representation formats (e.g., static or interactive, tables versus graphs, with or without transformations into new, semantically meaningful forms). The clarity of these representations may vary; however, given a complete representation, it will always be possible to apply formats that provide unambiguous, non-redundant, and non-excessive information about some realworld phenomena, whereas no modeling tool, however clear in the meaning of its constructs, can make an impoverished representation more complete. Therefore, in task settings of an explorative, rather than exploitative nature, the positive impact of combined ontological completeness of model combinations on users' ability to generate domain understanding might be strengthened whereas the negative impact of ontological overlap of model combinations on users' ability to generate domain understanding might be diminished.

It is also likely that these variations are not absolute. For example, when the demands for combined ontological completeness increase in task settings of an explorative nature, so does the cognitive load associated with processing that information presented to the user (Sweller, 1988). It is likely that there will be a tipping point in the positive impact of combined ontological completeness of model combinations on users' ability to generate domain understanding from a set of models, much like in the law of diminishing returns in economics (e.g., Samuelson and Nordhaus, 2001, p. 110): as the number of representations about a focal real-world phenomena 
covered through conceptual models increases, the relative gains in domain understanding will diminish, once the bearable level of cognitive load is surpassed (Miller, 1956). This effect is likely higher in task settings of explorative rather than exploitative nature, because the intrinsic load of these tasks is higher due to their emphasis on discovery learning over schema application (Tuovinen and Sweller, 1999), meaning less information processing capacity remains available in the working memory to process the external information in the models (Sweller, 1988; Chandler and Sweller, 1991).

\section{Prior Domain Knowledge}

A third variable relates to the influence of individual-level attributes characterizing the model reader. As we discuss above, our theory is not a theory of pragmatics or cognitive psychology that would explain how individuals come to learn new knowledge from conceptual models - the theory merely states why attributes of models influence users' interpretation (Shanks et al., 2008; Bera et al., 2014; Burton-Jones et al., 2017).

There has been some work that demonstrated that individual-level variables influence the extent to which users develop domain understanding from conceptual models. Amidst variables such as grammar familiarity (Recker, 2010), modeling experience (Mendling et al., 2012), schema expertise (Khatri and Vessey, 2016) and analyst role (Samuel et al., 2015), prior domain knowledge (Khatri et al., 2006; Bera et al., 2014) stands out as the most widely studied user characteristic in this context.

Prior domain knowledge captures the realm of knowledge an individual has about a particular real-world domain (Alexander, 1992). It describes the mental model individuals have about a domain, and which they use as a basis for internalizing new knowledge presented to them through one or more conceptual models about the domain. In other words, prior domain knowledge determines how much "new information" a model or set of models holds for the person reading it (Mayer, 2009). 
Recent evidence about the influence of prior domain knowledge on individuals' ability to generate domain understanding from interpreting a conceptual model suggests a nonlinear moderation effect in the form of a downward concave curve (Bera et al., 2014): too little or too high prior domain knowledge renders the information in a model either too complex or too redundant if the model is not completely clear.

A similar variation may occur when individuals with very high levels of prior domain knowledge interpret multiple conceptual models: as the level of combined ontological completeness increases, the likelihood that information is added that is already present in the mental model of the reader also increases, in turn only adding non-essential, redundant information that not only fails to add new knowledge for internalization but also renders the information processing more difficult as more cognitive effort must be devoted to identifying additional representational elements and matching them to those already stored in the working memory. Yet, ontological overlap of multiple models may not affect individuals with very high levels of prior domain knowledge much because they can use their knowledge to overcome any such ambiguities (Bera et al., 2014).

When individuals with very low levels of prior domain knowledge interpret multiple conceptual models on the other hand, higher levels of combined ontological completeness and ontological overlap might both have the same effect, that of adding extraneous load to a working memory already operating at capacity (Miller, 1956): readers with little to no domain knowledge already have difficulties internalizing even a clear single conceptual model because they "have an insufficiently developed mental model to incorporate much meaning [...] at all" (Bera et al., 2014 , p. 403). When assimilation of a relatively small set of new information fails to occur, it is unlikely that the provision of a more complete and thus larger set of new information, let alone one that contains overlap, will be of any benefit. 